NBER WORKING PAPER SERIES

THE EMPLOYMENT AND OUTPUT EFFECTS OF SHORT-TIME WORK IN GERMANY

\author{
Russell Cooper \\ Moritz Meyer \\ Immo Schott \\ Working Paper 23688 \\ http://www.nber.org/papers/w23688 \\ NATIONAL BUREAU OF ECONOMIC RESEARCH \\ 1050 Massachusetts Avenue \\ Cambridge, MA 02138 \\ August 2017
}

This research project has received funding from the European Union's 7th Framework Programme (FP7/2007-2013) under grant agreement 262608, DwB - Data without Boundaries. We declare that we have no relevant or material financial interests that relate to the research described in this paper. The views expressed herein are those of the authors and do not necessarily reflect the views of the National Bureau of Economic Research. Findings, interpretations, and conclusions expressed in this work do not necessarily reflect the views of the World Bank or any affiliated organizations, its Board of Executive Directors, or the governments they represent. The World Bank does not guarantee the accuracy of the data included in this work.

NBER working papers are circulated for discussion and comment purposes. They have not been peer-reviewed or been subject to the review by the NBER Board of Directors that accompanies official NBER publications.

(C) 2017 by Russell Cooper, Moritz Meyer, and Immo Schott. All rights reserved. Short sections of text, not to exceed two paragraphs, may be quoted without explicit permission provided that full credit, including $\odot$ notice, is given to the source. 
The Employment and Output Effects of Short-Time Work in Germany

Russell Cooper, Moritz Meyer, and Immo Schott

NBER Working Paper No. 23688

August 2017

JEL No. E24,E32,E65

\begin{abstract} policy intervention.

Russell Cooper

Department of Economics

The Pennsylvania State University

611 Kern

State College, PA 16802

and NBER

russellcoop@gmail.com

Moritz Meyer

World Bank

1818 H Street N.W.

Washington, DC 20433

meyer.moritz@gmail.com

Immo Schott

Université de Montréal

immo.schott@umontreal.ca
\end{abstract}

We study the employment and output effects of the short-time work (STW) policy in Germany between 2009 and 2010. This intervention facilitated reductions in hours worked per employee with the goal of preventing layoffs. Using confidential German micro-level data we estimate a search model with heterogeneous multi-worker firms as a basis for policy analysis. Our findings suggest that STW can prevent increases in unemployment during a recession. However, the policy leads to a decrease in the allocative efficiency of the labor market, resulting in significant output losses. These effects arise from a reduction in the vacancy filling rate resulting from the 


\title{
The Employment and Output Effects of Short-Time Work in Germany*
}

\author{
Russell Cooper ${ }^{\dagger}$ and Moritz Meyer ${ }^{\ddagger}$ and Immo Schott ${ }^{\S}$
}

August 3, 2017

\begin{abstract}
We study the employment and output effects of the short-time work (STW) policy in Germany between 2009 and 2010. This intervention facilitated reductions in hours worked per employee with the goal of preventing layoffs. Using confidential German micro-level data we estimate a search model with heterogeneous multi-worker firms as a basis for policy analysis. Our findings suggest that STW can prevent increases in unemployment during a recession. However, the policy leads to a decrease in the allocative efficiency of the labor market, resulting in significant output losses. These effects arise from a reduction in the vacancy filling rate resulting from the policy intervention.
\end{abstract}

\section{Introduction}

In 2009 Germany experienced the largest drop in GDP among OECD countries. Figure 1 shows that GDP fell by $6.9 \%$ in the first quarter of 2009 (OECD average -4.8\%). As Figure 2 shows, the German unemployment rate increased by less than one percentage point. This experience stands in sharp contrast to other OECD economies, where the unemployment rate increased markedly during the recession and in many cases remained high in the post-crisis period.

The economic press has largely attributed this 'German miracle' to the use of 'short-time work' (STW) or 'short-time compensation'. In this paper we ask whether STW played an important role in explaining the distinct response of the German labor market.

STW describes a policy instrument which aims at mitigating the negative impact of shocks on the labor market. It enables firms to reduce labor demand via the intensive margin (the number of hours worked per

${ }^{*}$ We thank Michael Burda, Thomas Lemieux, Baris Kaymak, Guido Menzio, Ben Pugsley, and participants at various seminars and conferences for helpful comments. This research project has received funding from the European Union's 7th Framework Programme (FP7/2007-2013) under grant agreement №262608, DwB - Data without Boundaries. We declare that we have no relevant or material financial interests that relate to the research described in this paper. The findings, interpretations, and conclusions expressed in this work do not necessarily reflect the views of the World Bank or any affiliated organizations, its Board of Executive Directors, or the governments they represent. The World Bank does not guarantee the accuracy of the data included in this work.

${ }^{\dagger}$ Department of Economics, Pennsylvania State University and NBER, russellcoop@gmail.com

${ }^{\ddagger}$ The World Bank, moritz.meyer@gmail.com

${ }^{\S}$ Department of Economics, Université de Montréal and CIREQ, immoschott@gmail.com 


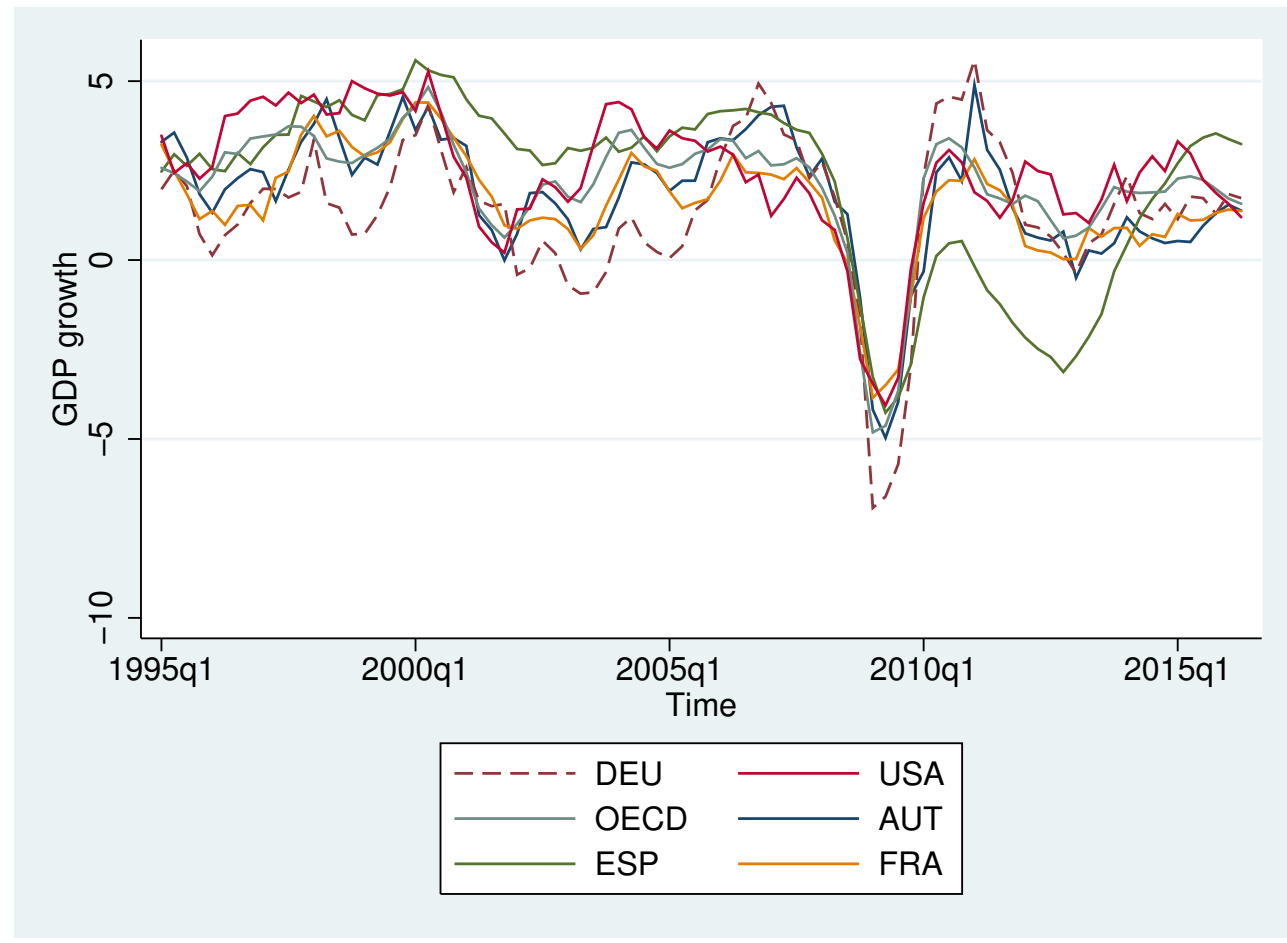

Figure 1: GDP Growth

Quarterly GDP growth compared to one year ago for selected OECD-countries. The y-axis shows the growth rate in \%. The red dashed line shows Germany. Source: OECD.

employee) instead of the extensive margin (the number of employees). Firms that want to temporarily reduce hours per worker must formally apply for STW. Approval is subject to a strict set of legal requirements 11 Absent approved use of STW, unilateral reductions in hours worked below the contracted number of hours are not legal. Workers affected by STW are eligible for a partial compensation of their earnings loss.

In 2009 the STW instrument was significantly extended. For the remainder of this paper, this extension will be referred to as the 'STW policy'. The German government dramatically loosened the eligibility criteria for firms and significantly expanded the policy's scope $2^{2}$ During the recession years of 2009 and 2010 the German government compensated $60 \%$ (67\% for workers with children) of the net earnings difference due to a working hours reduction. Hours worked were paid as usual $]^{3}$ Newspaper ads were taken out by the government to

\footnotetext{
${ }^{1}$ The German Code of Social Law, Book 3 (SGB III) defines short-time work. The requirements for STW are 1.) The hours reduction must not be preventable, meaning employees must not have accumulated overtime or holidays, and the firm must be unable to compensate the work stoppage with variations in intra-firm working hours that are permissible according to the work contract. 2.) At least a third of the firm's workforce must suffer an earnings loss of at least 10\%. 3.) The firm must show that it is facing a temporary reduction in working time due to an economic downturn. The maximum duration of STW is six months. The firm must show that after this time full-time employment can be restored. There exist three different forms of short-time work: 1.) Due to economic distress $(\S 170), 2$.) seasonal fluctuations (§175) 3.) transfer payments mainly during the German reunification $(\S 216 \mathrm{~b})$. In this paper we focus exclusively on the first type. The use of other types of STW has not significantly changed during the period under consideration.

${ }^{2}$ Eligibility criteria 2) and 3) referred to in footnote 1 were loosened. Most importantly, firms no longer needed to show that the hours reduction would only last a maximum of six months. The employers' contribution to social security was initially paid in full by the firm. In a subsequent modification, the employers' social security contribution was made proportional to actual hours worked or even paid in full by the government in special cases.

${ }^{3}$ During STW, a firm continues to pay an affected worker's social security contributions in full. These 'remanence costs' increase
} 


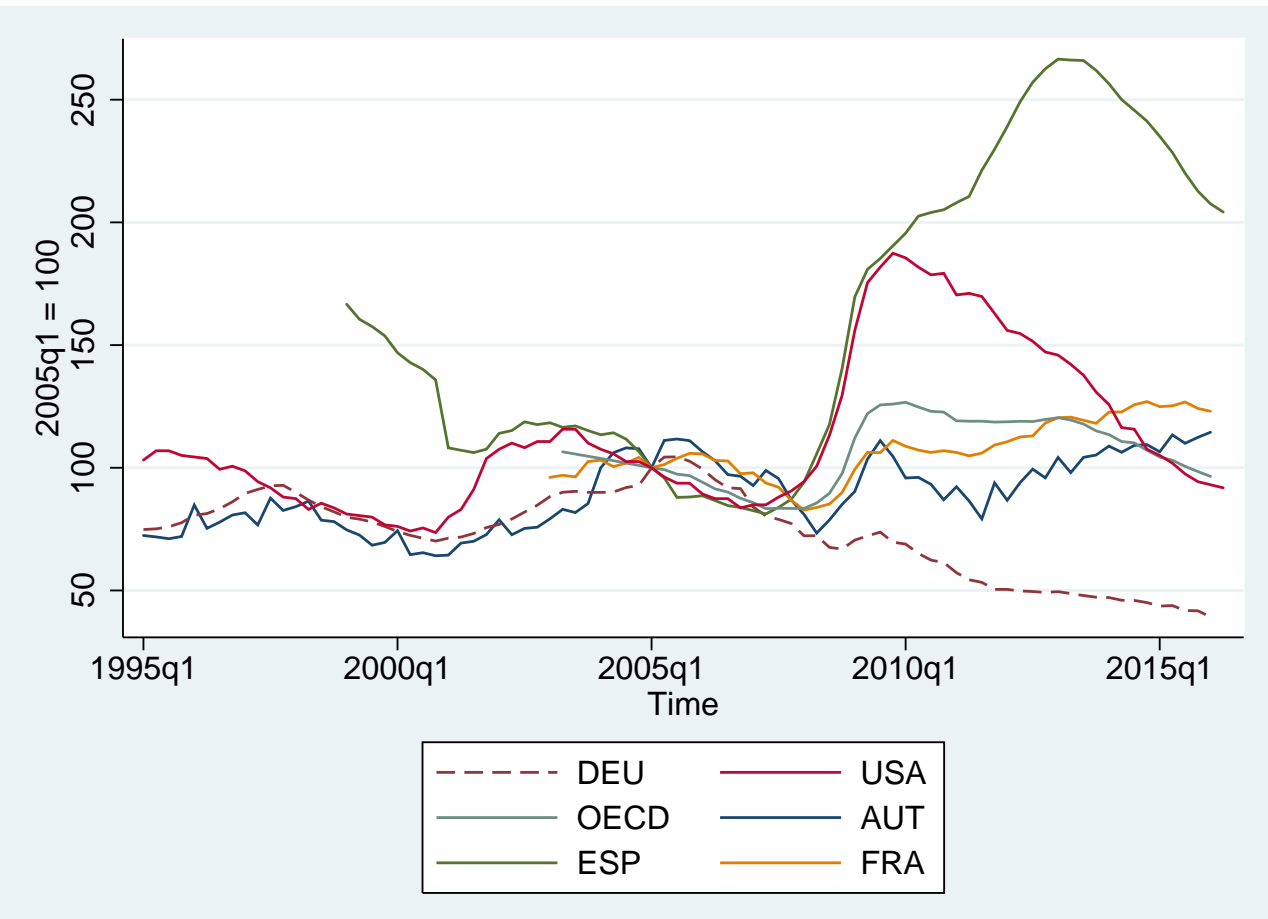

Figure 2: Unemployment Rate

Unemployment Rates for selected OECD-countries. 2005q1 $=100$. The red dashed line shows Germany. Source: OECD.

encourage firms to apply for STW. The maximum duration of STW was extended from six to 18 and later 24 months. At its height the program included around 60,000 establishments and approximately 1.5 million workers (about $3.5 \%$ of the labor force) 4 The extension of the policy was reversed in 2010.

In our analysis, the choice of the labor input is placed in a search context with multi-worker firms, following Cooper, Haltiwanger, and Willis (2007), allowing for bargaining between a firm and its workers, as in Elsby and Michaels (2013). Multi-worker firms are subject to persistent aggregate and idiosyncratic productivity shocks and choose both employment and hours worked. We use confidential German plant-level micro data on the universe of German manufacturing plants (the 'AFiD-Panel Industriebetriebe') in order to estimate a structural model of the German labor market. Our quantitative exercise uses a simulated method of moments (SMM) approach to match the distributions of hours and changes in German firms prior to the policy.

We use the model to address two questions: (i) can short-time work save jobs? and (ii) what are the costs of STW in terms of output and productivity? We answer these questions by simulating a counterfactual scenario to determine the response to the recession without STW. Our results indicate that STW can save jobs. However, the policy has negative effects on output. From our estimated model, in the absence of STW, the output loss during the recession would have been $5.3 \%$ and unemployment would have risen by about four percentage points. The German 'miracle' would largely disappear.

\footnotetext{
the hourly wage through over-proportional social security payments.

${ }^{4}$ In May 2009 there were 1,442,667 workers on STW for economic reasons, up from 39,697 a year earlier. In the Appendix we give more details about the uptake of the policy over time.
} 
The key to the effects of the STW is reallocation. Under the policy, productive firms find it more costly to hire labor as fewer workers are released into the unemployment pool. In market economies the efficiency of the allocation of factors across production sites has been shown to play an important role for aggregate productivity (see Hsieh and Klenow (2009), Bartelsman, Haltiwanger, and Scarpetta (2013), Cooper and Schott (2016)). By intervening into the reallocation of factors across production sites, i.e. preventing labor from flowing towards the most productive firms, STW can generate adverse effects on GDP through this 'reallocation channel'. To uncover this channel, it is important to take the firm size and productivity distribution into account by explicitly accounting for firm heterogeneity.

Our model studies the composition of the labor input in response to the STW policy. Burdett and Wright (1989) model the choice of hours and employees in a static contracting environment. They establish how the introduction of unemployment insurance and/or short-time work can influence how the adjustment of labor input is decomposed into changes in average hours and the number of workers. The use of a search model, as in our analysis, naturally creates a setting which distinguishes the number of workers from the intensive margin of hours worked as the former matters for the determination of search frictions.

Other papers which study the STW policy in Germany during 2009 and 2010 include Burda and Hunt (2011), Dustmann, Fitzenberger, Schönberg, and Spitz-Oener (2014), Balleer, Gehrke, Lechthaler, and Merkl (2016), Cahuc and Carcillo (2011), and Hoffmann and Lemieux (2016).5 Burda and Hunt (2011) provide an overview of the institutional framework in Germany. They conclude that the main reasons for the performance of the German labor market during the years 2009/10 were a reticence to hire in the previous expansion, wage moderation, and flexibility in hours worked (mainly through STW but also through working-time accounts). Balleer et al. (2016) build a search and matching model in which heterogeneous workers can be put on STW. In their model a persistent STW 'policy shock' generates positive output and employment effects because firms can reduce the working times of unprofitable workers. Our model is different from Balleer et al. (2016) because we consider heterogeneous firms and homogeneous workers. This allows us to study the productivity implications of the allocation of workers to firms. Another important difference is that we explicitly allow for an intensive margin of labor demand, even absent the STW policy ${ }^{6}$ In contrast to much of the previous research on the German labor market (e.g. Krause and Uhlig (2012), and Cahuc and Carcillo (2011)) we highlight the importance of firm heterogeneity, both in the data and in our model. Representative firm models as in Marimon and Zilibotti (2000) and Kudoh and Sasaki (2011), as well as reduced-form relationships ignore this heterogeneity and are therefore unable to capture the effects of STW on labor reallocation and output.

Competing explanations of the German employment 'miracle' during the last recession stress the importance of the labor market reforms in the early 2000s (the so-called 'Hartz-reforms'), a reticence to hire in the previous expansion, and the adoption of working-time accounts (Burda and Hunt (2011)). We do not find these alternative explanations to be sufficient.

The 2005 Hartz-reforms were primarily aimed at reducing the generosity of long-term unemployment insurance, thereby increasing the job acceptance probabilities of unemployed workers. These reforms had no direct

\footnotetext{
${ }^{5}$ As noted above, this paper is also related to the literature on the efficacy of hours reductions in static firm models (see e.g. Burdett and Wright (1989), Hunt (1998, 1999), Braun and Brügemann (2014)).

${ }^{\circ}$ Selective application of STW to specific workers is largely impossible in Germany due to legal constraints (see e.g. Kruppe and Scholz (2014)).
} 
impact on the employers' flexibility to adjust hours ${ }^{7}$

Further, in our employment data for the universe of German manufacturing firms, we do not see evidence for a reticence to hire in the period prior to the 2009 recession. Figure 3 shows that that aggregate employment growth was positive between 2006 and 2008.

Burda and Hunt (2011) highlight that intensive margin employment adjustments are difficult due to institutional constraints and that firms increasingly took advantage of the flexibility through working-time accounts. ${ }^{8}$ We test the robustness of our results with respect to firms' flexibility in hours adjustment absent STW. This is meant to reflect the growing importance of working-time accounts. Balleer et al. (2016) provide evidence that during the Great Recession firms did not substitute working time accounts for short-time work. They find that firms with working time accounts more frequently used short-time work to adjust employment than firms without working time accounts. Furthermore, working-time accounts typically need to be balanced at the end of the year.

\section{Data}

Our micro data comes from the 'AFiD-Panel Industriebetriebe', a confidential panel of the universe of German manufacturing plants administered by the German Federal Statistical Office in cooperation with the statistical offices of the German Länder. The panel contains annual data from plants with more than 20 employees between 1995 and 20109 It covers a maximum of 68,000 plants per year. Participation in the surveys is mandatory. For the purposes of this paper we use an unbalanced panel of 39,180 plants ${ }^{10}$

Our focus on the manufacturing sector is warranted for the purpose of this paper because the use of STW was heavily concentrated in that sector. At the height of the STW program in 2009, over $80 \%$ of workers and $45 \%$ of plants that used STW were operating in the manufacturing sector and $16.9 \%$ of all manufacturing employees were on STW (see Appendix). In Germany, employment in this sector is heavily concentrated in medium-sized and/or family-owned firms (German Mittelstand). Including these firms is therefore crucial in any assessment of labor market policies. Using administrative micro data drastically reduces sampling bias and allows for a clear identification of the effect of the policy on employer behavior. A shortcoming of the data is that it contains no direct information on whether or not a plant used short-time work, in contrast to Niedermayer and Tilly (2016) and Balleer et al. (2016). Despite the lack of direct information, this section produces ample evidence that the

7 Krause and Uhlig (2012) evaluate the impact of those reforms on employment. They find a large reduction in unemployment due to the reforms but attribute the behavior of the German labor market during the 2009 recession to STW, which they do not model. Contrary to our approach, the search model in Krause and Uhlig (2012) is in large parts calibrated to the US labor market.

${ }^{8}$ According to Burda and Hunt (2011) positive balances on working-time accounts have initially allowed firms to lower working hours without laying-off employees but they do not explain why the unemployment rate remained low even when this first buffer was fully exhausted. Firms were required to fully balance working-time accounts and reduce accrued holidays before being eligible for short-time work. In their Table 7, (p. 300) they show that short-time work constituted the single most important source of changes in hours per worker between 2008/09.

${ }^{9}$ The data includes smaller plants if they belong to a firm with at least 20 employees. For the years 2007 to 2010 the cutoff to be included in the survey was increased to 50 employees. In our data this change did not significantly influence the distribution of our variables of interest, also because many smaller plants continued to provide the information. Furthermore, in the Appendix we show that the vast majority of workers on STW worked in medium and large firms.

${ }^{10}$ We start with 59,268 unique plants before winsorizing the data. Plants with less than three consecutive observations account for 2.8 percent of all plant-year observations and were deleted from the final sample. This leaves on average 39,180 plants per year. Of those, 19,373 plants were observed for all years between 1995 and 2010. 


\begin{tabular}{|c|c|c|c|c|c|c|c|}
\hline & Count & Mean & SD & IQR & p10 & Median & p90 \\
\hline \hline$N$ & 38,839 & 98.5 & 142.6 & 73.8 & 19.4 & 48.2 & 228.0 \\
\hline$H$ & 33,617 & 156,300 & 20,576 & 11,694 & 3,578 & 8,366 & 35,107 \\
\hline$H / N$ & 34,303 & 135.8 & 35.7 & 31.6 & 104.5 & 134.0 & 167.9 \\
\hline$P Y$ & 39,180 & $1,531,785$ & $3,106,538$ & $1,116,285$ & 101,242 & 474,343 & $3,766,944$ \\
\hline
\end{tabular}

Table 1: Summary Statistics

Summary statistics for Employment $N$, Hours $H$, Hours per Employee $H / N$, and Revenue $P Y$. The table shows average values over all years. Revenues are deflated to 2005 Euros. Source: AFid Panel Industriebetriebe

effect of the policy is visible in our sample.

Descriptive statistics are shown in Table 1. The table shows time-series averages of total employment, total hours, hours per worker, and revenues. The average number of employees is 98.5 . More than $50 \%$ of plants employ less than 50 workers, whereas the largest $10 \%$ employ more than 220 workers. Average hours worked at the plant level are computed as total hours worked divided by total employment. The large differences between the 10th and the 90th percentile of the distribution of revenues illustrate substantial plant heterogeneity. The 2009 recession is clearly visible in our micro data: Between 2008 and 2009 mean (median) revenues fell by $9 \%$ $(12 \%)$.

We use the micro data to decompose changes in total hours worked into an intensive and an extensive margin. Figure 3 shows a large reduction in total hours worked in 2009, with a reversal in 2010. The figure not only shows that the reduction in total hours was unprecedented, it also reveals that almost $70 \%$ of it was driven by reductions in hours per worker. We attribute this to the use of STW. In previous recessions, for example in 2003, there was no similar extension of the STW instrument and also no comparable decrease in average hours.

The fact that Kurzarbeit created an unprecedented flexibility in average hours is central to this study. This flexibility is highlighted in Figure 4, which shows the distribution of changes in average hours. The years 19952008 (blue) serve as references years, while the year 2009 (red) is the year of the STW policy. In 2010 (green) the policy was phased out. The figure shows the share of plants adjusting hours within a given interval for each of the three different time periods. We define inactive plants as those who adjust annual hours by less than $5 \%$.

Three things stand out: 1.) Adjustments in average hours are prevalent, 2.) the hours change distribution between 1995 and 2008 is characterized by many small adjustments of less than $5 \%$ (including inactivity), whereas large adjustments of over $20 \%$ in average hours worked are rare, and 3.) in 2009 the distribution significantly shifts towards negative hours adjustments. Only looking at aggregates in the number of hours worked per employee thus hides substantial heterogeneity among plants. The impact of the STW policy is clearly visible in our data: The fraction of plants that reduced average hours by more than $20 \%$ more than tripled in 2009. This unprecedented shifts reflects the ability of plants to reduce hours worked as a results of the STW policy. These negative hours adjustments were reversed in 2010, where large positive adjustments are prevalent in the data. 


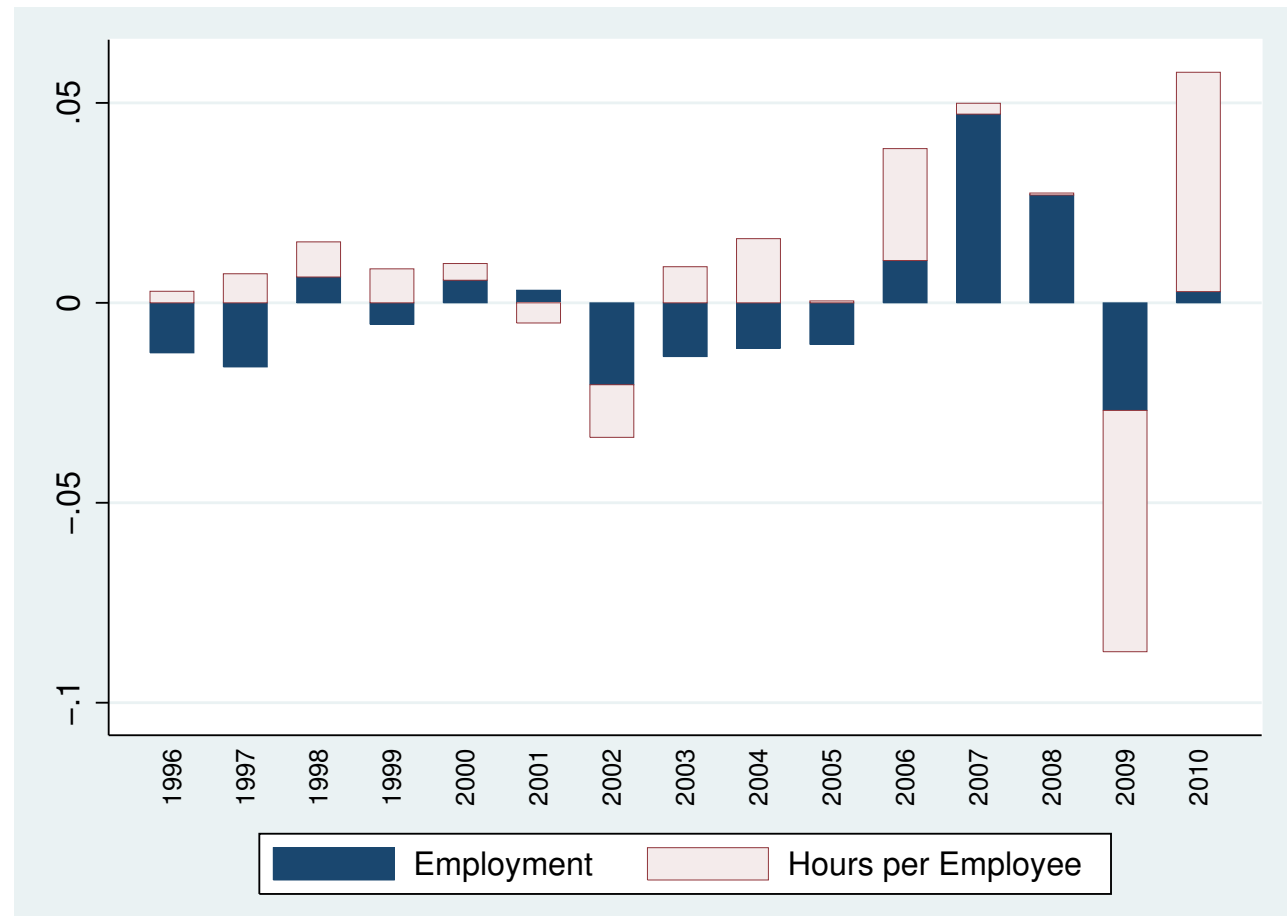

Figure 3: Changes in Total Hours

Decomposition of changes in total hours into the intensive and the extensive margin. The yaxis shows differences of the logarithm of total hours worked. The numbers are calculated using the average changes from the micro data. Source: Authors' calculations from the AFiD-Panel Industriebetriebe.

\section{Model}

In the next sections, we construct and estimate a search model of the labor market. The model is used to evaluate the effects of STW on the German economy.

We first describe the stationary economy without any constraints on firms' hours choices and without aggregate shocks. In the next subsection, we model the German labor market by imposing a lower bar on hours, below which firms cannot operate, $h \geq \underline{\mathrm{h}}$. The STW policy removes this constraint and provides income support for workers whose hours are reduced.

The economy is populated by workers, firms, and a government. The time period is one month. Firms are subject to persistent, time-varying idiosyncratic productivity shocks $\varepsilon$. Firms choose the number of workers $n$ and average hours $h$. Workers are homogeneous. The labor market is frictional. There exists a constant returns to scale matching technology $M=m(U, V)$, with the unemployment rate $U$ and the vacancy rate $V$ as inputs. The labor market tightness $\theta=V / U$ is a sufficient statistic for the job finding and vacancy filling probabilities. A vacancy is matched to a worker during a period with probability $q=M / V=m\left(\frac{U}{V}, 1\right)$. A worker finds a job with probability $\phi=q \theta$. 


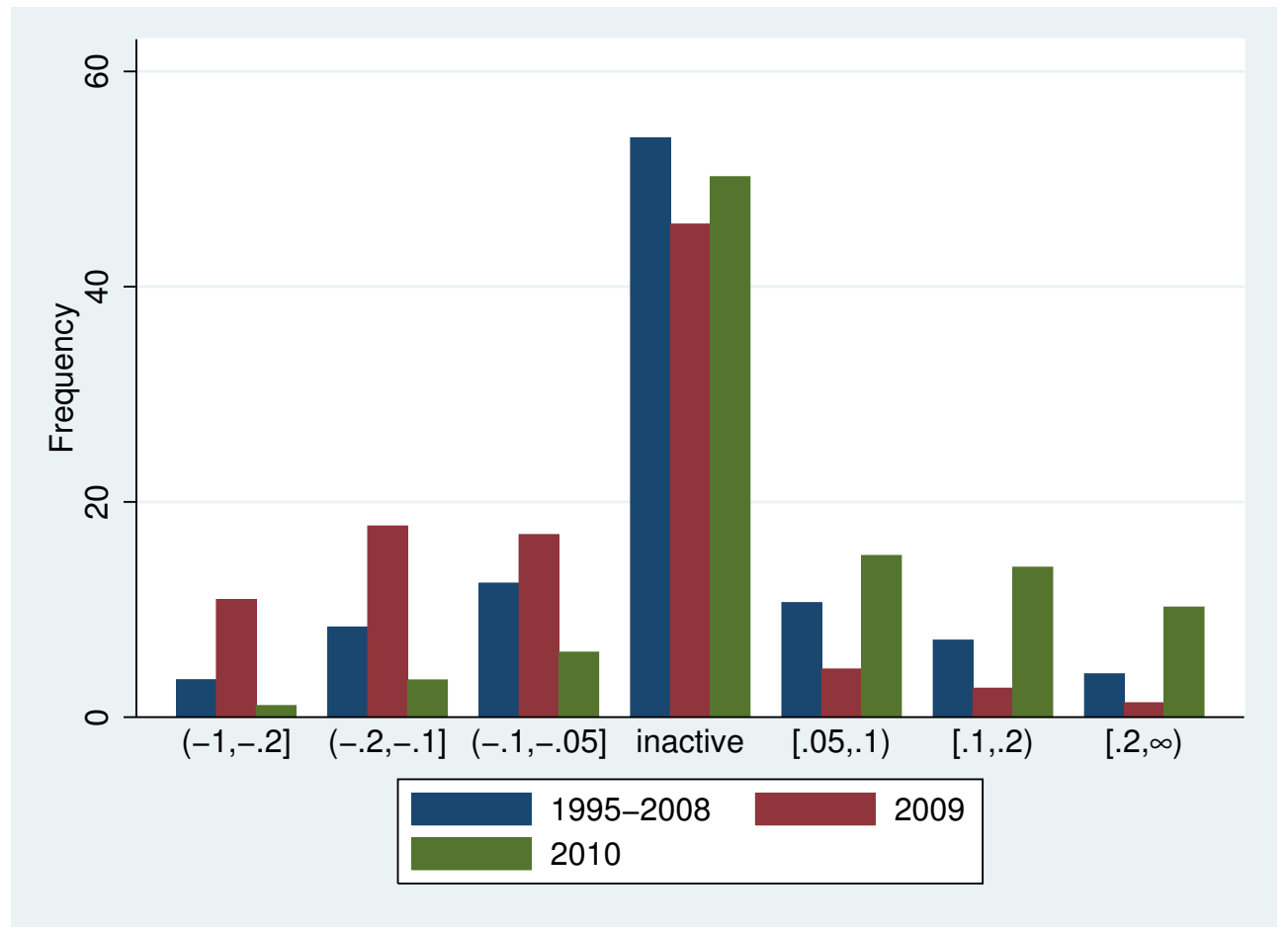

Figure 4: Changes in Annual Hours per Worker

Distribution of changes in annual hours per worker. The data is computed using year-to-year changes at the establishment-level. The different bins show the fraction of plants that changed the annual hours per worker by the indicated amount. Within each bin the order of the time periods is 1995-2008, 2009, 2010. Source: Authors' calculations from the AFiD-Panel Industriebetriebe.

\subsection{Economy without Hours Constraints}

This sub-section describes the optimization problem of firms as well as the values of employment and unemployment for workers. Using these values, a wage function is obtained as the outcome of a bargain between a firm and multiple workers.

Firms The production technology uses labor as the only input and is given by $F(L)$. Define $L \equiv h \cdot n$ as total labor input, composed of the number of workers $n$ and average hours $h$. The production function $F(L)$ is assumed to be strictly increasing and strictly concave. Hours adjustments are costless and instantaneous. Adjustments in the number of workers are costly because of the existence of vacancy creation costs.

The timing is as follows: At the beginning of a period the firm has $n_{-1}$ workers and learns about its idiosyncratic productivity state $\varepsilon$. A firm in state $\left(\varepsilon, n_{-1}\right)$ chooses $n$ (equivalently, posts vacancies) and $h$ to determine its scale of production. The compensation it pays, given its choice of $h$ and $n$ is determined by a compensation schedule, detailed below. If a firm is hiring (shown by the indicator function $\mathbb{1}^{+}$), the change in employment is given by $n=n_{-1}+q v$. Taking into account the vacancy filling probability $q$ the firm can perfectly choose the level of employment $n$. If a firm is firing then $n=n_{-1}-f$. There are no firing costs and 
no exogenous quits. The firm's expected present discounted value in state $s=\left(\varepsilon, n_{-1}\right)$ is given by

$$
V\left(\varepsilon, n_{-1}\right)=\max _{h, n}\left\{\varepsilon F(h \cdot n)-\omega(h, n, \varepsilon) \cdot h \cdot n-\frac{c_{v}}{q}\left(n-n_{-1}\right) \mathbb{1}^{+}+\beta \int V\left(\varepsilon^{\prime}, n\right) d G\left(\varepsilon^{\prime} \mid \varepsilon\right)\right\} .
$$

Here $c_{v}$ is a linear vacancy creation cost. The discount factor is $\beta$. Worker compensation per hour is $\omega(\cdot)$, which will be derived below.

The FOC with respect to hours is given by

$$
\varepsilon F_{L}(h \cdot n)-\omega(h, n, \varepsilon)-\omega_{h}(h, n, \varepsilon) \cdot h=0
$$

The firm chooses hours to equalize the marginal benefit from increasing total labor input by an additional hour with the marginal cost: The wage must be paid for one additional hour of work and existing workers have to be paid an increased wage to compensate for the hours increase. Let $\mathcal{H}(\varepsilon, n)$ denote the optimal choice of hours given $(\varepsilon, n)$ that solves $(2)$.

If $\Delta n \neq 0$ the first order condition for $n$ yields

$$
\varepsilon h F_{L}(h \cdot n)-\omega(h, n, \varepsilon) \cdot h-\omega_{n}(h, n, \varepsilon) \cdot n h-\frac{c_{v}}{q} \mathbb{1}^{+}+\beta D(\varepsilon, n)=0
$$

where $D(\varepsilon, n) \equiv \int V_{n}\left(\varepsilon^{\prime}, n\right) d G\left(\varepsilon^{\prime} \mid \varepsilon\right)$ is the marginal effect of current employment choices on the expected future value of the firm. The firm changes employment until the point where the marginal benefit of the employment change is equal to the expected marginal cost. The marginal benefit of an additional worker is given by the change in output plus the expected effect on the future value of the firm. The marginal costs include the additional hiring costs and the changes in wage payments.

As stated, the model excludes job to job flows. Given the magnitude of these flows in Germany, this omission from the model is not crucial. Between 1985 and 2010 the average job-to-job transition rates of fulltime employees was $0.5 \%$. Ravenna and Schott (2016) document that the job-to-job transition rates during the 2009 recessions were not significantly different from previous recessions.

In addition, the model abstracts from firm entry and exit. The moments from the balanced and unbalanced panels are almost identical, due to the fact that entry and exit rates in manufacturing are very low. There is no evidence that entry and exit rates changed during the policy years.

Workers Workers' preferences are defined over consumption and leisure. The disutility from providing hours is given by $\xi(h)$. We assume that $\xi^{\prime}(h)>0, \xi^{\prime \prime}(h)>0$, and $\xi(0)=0$. Workers are assumed to be risk-neutral. They can be either unemployed or employed 11

The value of being employed in a firm in state $(\varepsilon, n)$ is given by

$$
W^{e}(\varepsilon, n)=\omega(h, \varepsilon, n) \cdot h-\xi(h)+\beta \mathbb{E}_{\varepsilon^{\prime}, n^{\prime} \mid \varepsilon, n}\left[s W^{u}+(1-s) W^{e}\left(\varepsilon^{\prime}, n^{\prime}\right)\right]
$$

\footnotetext{
${ }^{11}$ Both Burdett and Wright (1989) and Cooper et al. (2007) allow for worker risk aversion and emphasize the role of insurance in labor contracts. Risk sharing is fundamental to their view of wage determination. For this analysis, risk sharing could be incorporated into the analysis as well but the main point is to highlight the trade-off between intensive and extensive margin adjustments due to STW.
} 
where $h=\mathcal{H}(\varepsilon, n)$. An employed worker's instantaneous utility consists of the hourly wage $\omega(\cdot)$ times $h$ hours worked minus the disutility from providing $h$ hours. A match can be (endogenously) severed with probability $s$. In that case the worker becomes unemployed next period and receives the future value of being unemployed, $W^{u}$. With the counter-probability the worker remains employed in the firm, which is then in state $\left(\varepsilon^{\prime}, n^{\prime}\right)$. The expectation is taken over possible future levels $\varepsilon^{\prime}$ conditional on today's value of $\varepsilon$.

The value of being unemployed is given by

$$
W^{u}=b+\beta \mathbb{E}_{\varepsilon^{\prime}, n^{\prime} \mid \varepsilon, n}\left[(1-\phi) W^{u}+\phi W^{e}\left(\varepsilon^{\prime}, n^{\prime}\right)\right] .
$$

The instantaneous utility for an unemployed worker is the (exogenous) payoff $b$. With probability $1-\phi$ the worker remains unemployed. With the counter-probability a match is formed with a hiring firm. That firm will be in state $\left(\varepsilon^{\prime}, n^{\prime}\right)$ tomorrow. The expectation is taken over the distribution of $\left(\varepsilon^{\prime}, n^{\prime}\right)$ among hiring firms.

Wage Setting Because of the labor market frictions, quasi-rents exist from forming a match over which workers and firms bargain 12 This gives rise to a wage function which depends on the productivity level, as well as hours and employment choices of the firm. This wage function is obtained through a Nash bargain by a representative firm and identical workers.

Since the production technology features decreasing returns to scale, we adopt the bargaining solution first proposed in Stole and Zwiebel (1996) by extending the framework in Elsby and Michaels (2013) to include hours worked. The bargain is over wages, taken as given that firms will optimally select hours given the compensation function, as in (1) 13 A worker's surplus from forming a match is given by the value of being employed in a firm in state $(\varepsilon, n)$ minus the value of being unemployed. The firm's marginal surplus of forming the match with any given worker is given by

$$
S(\varepsilon, n)=\varepsilon h F_{L}(h \cdot n)-\omega(h, n, \varepsilon) h-\omega_{n}(h, n, \varepsilon) h n+\beta D(\varepsilon, n)
$$

with $h=\mathcal{H}(\varepsilon, n)$.

Wages are determined after employment, meaning that hiring costs are sunk. The bargaining power of the worker is parameterized as $\eta$. Nash-bargaining over the marginal surplus implies that the surplus is shared according to

$$
W^{e}(\varepsilon, n)-W^{u}=\frac{\eta}{1-\eta} S(\varepsilon, n) .
$$

The wage solves the following differential equation: 14

$$
\omega(h, \varepsilon, n) \cdot h=(1-\eta)[b+\xi(h)]+\eta\left[\varepsilon h F_{L}(h \cdot n)+\beta \phi \frac{c_{v}}{q}-\omega_{n}(h, n, \varepsilon) \cdot h \cdot n\right] .
$$

Wages are increasing in the worker's bargaining power, the marginal product of labor, the hiring costs, the value of leisure, and the disutility of labor. The term $w_{n}(h, n, \varepsilon) \cdot h \cdot n$ represents the effect of a marginal worker

\footnotetext{
${ }^{12}$ As suggested by Dustmann et al. (2014), we consider bargaining between a firm and its workers rather than national bargaining.

13 Brügemann, Gautier, and Menzio (2015) argue there is an inconsistency in the framework of Stole and Zwiebel (1996) and propose an alternative extensive form game to support the Shapley value outcome.

${ }^{14}$ All the expressions to solve (7) and derive the wage can be found in Appendix B.
} 
on the firm's marginal product of labor. If the negotiations were to fail, this increases all the other workers' marginal product of labor, thus increasing the average wage payments for the firm. With respect to Elsby and Michaels (2013) there is an additional effect from the disutility of providing hours: the optimal choice of hours influences the effect a marginal worker can have on the marginal product of labor. By choosing higher average hours, the firm can decrease the marginal product and partially offset the spillover into the remaining workers' marginal product in case of a failed wage negotiation.

For the remainder of the analysis, assume $F(h \cdot n)=(h \cdot n)^{\alpha}$. The total wage paid per worker is given by

$$
\omega(h, \varepsilon, n) \cdot h=(1-\eta)[b+\xi(h)]+\eta\left[\frac{\varepsilon \alpha h^{\alpha} n^{\alpha-1}}{1-\eta(1-\alpha)}+\beta \phi \frac{c_{v}}{q}\right] .
$$

Optimal Labor Demand Given the wage in (9), we can solve for firm's hours choice analytically. Plugging the wage into (2), the first order condition for hours, we obtain

$$
h^{*}=\left[\frac{\varepsilon \alpha n^{\alpha-1}}{\xi^{\prime}\left(h^{*}\right)(1-\eta(1-\alpha))}\right]^{\frac{1}{1-\alpha}} .
$$

This determines the firm's hours policy $\mathcal{H}(\varepsilon, n)$. The firm's employment policy can be obtained by combining the first-order conditions for employment (3) with the wage (9):

$$
(1-\eta)\left[\frac{\varepsilon \alpha h^{\alpha} n^{\alpha-1}}{1-\eta(1-\alpha)}-(b+\xi(h))\right]-\eta \phi \frac{c_{v}}{q}-\frac{c_{v}}{q} \mathbb{1}^{+}+\beta D(\varepsilon, n)=0
$$

The optimal employment policy is defined by cutoff values in idiosyncratic productivity $\varepsilon$. If productivity today is below a certain threshold, the firm will fire workers. Similarly, if $\varepsilon$ is above a certain threshold, the firm will post additional vacancies. The cutoffs define a region of inactivity. The thresholds are denoted as $\psi_{v}$ and $\psi$. The inverse of the threshold values, $\psi_{v}^{-1}(\varepsilon)$ and $\psi^{-1}(\varepsilon)$, define the optimal choice of employment given the level of productivity $\varepsilon$ today. This employment policy will be denoted as $\mathcal{N}\left(\varepsilon, n_{-1}\right)$ and takes the form

$$
\mathcal{N}\left(\varepsilon, n_{-1}\right)= \begin{cases}\psi_{v}^{-1}(\varepsilon) & \text { if } \varepsilon>\psi_{v}\left(n_{-1}\right) \\ n_{-1} & \text { if } \varepsilon \in\left[\psi\left(n_{-1}\right), \psi_{v}\left(n_{-1}\right)\right] \\ \psi^{-1}(\varepsilon) & \text { if } \varepsilon<\psi\left(n_{-1}\right)\end{cases}
$$

where the functions $\psi_{v}(\cdot)$ and $\psi(\cdot)$ satisfy

$$
(1-\eta)\left[\frac{\psi_{v}(n) \alpha h^{\alpha} n^{\alpha-1}}{1-\eta(1-\alpha)}-(b+\xi(h))\right]-\eta \phi \frac{c_{v}}{q}+\beta \int V_{n}\left(\varepsilon^{\prime}, n\right) d G\left(\varepsilon^{\prime} \mid \psi_{v}(n)\right) \equiv \frac{c_{v}}{q}
$$

and

$$
(1-\eta)\left[\frac{\psi(n) \alpha h^{\alpha} n^{\alpha-1}}{1-\eta(1-\alpha)}-(b+\xi(h))\right]-\eta \phi \frac{c_{v}}{q}+\beta \int V_{n}\left(\varepsilon^{\prime}, n\right) d G\left(\varepsilon^{\prime} \mid \psi(n)\right) \equiv 0
$$


If $\varepsilon$ is time-invariant the first order condition for employment (3) reduces to

$$
n=\left(\frac{\varepsilon \alpha h^{\alpha}}{\Gamma}\left[\frac{1-\eta}{1-\eta(1-\alpha)}\right]\right)^{\frac{1}{1-\alpha}}
$$

where $\Gamma=(1-\eta)[b+\xi(h)]+\eta \phi \frac{c_{v}}{q}$. It increases if $\varepsilon$ increases and decreases with $b$ and the worker's disutility of labor. This expression will be used in the calibration of the model.

Distribution of Firms The distribution of firms over productivity and employment is denoted $\lambda\left(\varepsilon, n_{-1}\right)$. Its law of motion is governed by the process for idiosyncratic profitability shocks and the firm's employment policy function, $\mathcal{N}\left(\varepsilon, n_{-1}\right)$.

Equilibrium A stationary equilibrium consists of policy functions $\mathcal{N}\left(\varepsilon, n_{-1}\right)$ and $\mathcal{H}(\varepsilon, n)$, a stationary distribution $\lambda^{*}\left(\varepsilon, n_{-1}\right)$ and a wage schedule $\omega(\cdot)$, such that policy functions solve the firm's problem, the wage solves the bargaining problem between workers and firms, and the distribution $\lambda^{*}$ is a fixed point.

\subsection{Hours Constraint and Short-Time Work}

To capture the rigidities of the German labor market in terms of hours adjustments, we let $\underline{\mathrm{h}}$ represent some notion of 'normal' hours per worker, as in Burdett and Wright (1989) ${ }^{15}$ Firms must set $h \geq \underline{\mathrm{h}}$, which introduces an additional constraint on the firm optimization problem compared to the setup above, where implicitly $\underline{\mathrm{h}}=0$. We can now introduce the 'STW policy', which will be represented by the parameter $\Xi$. Firms that use the policy must set average hours subject to $h \geq \underline{h}-\Xi$. In this way the policy can have an effect on hours (and therefore also employment) by increasing $\Xi$ in an environment in which the lower bound on hours is binding. The policy parameter can take values $\Xi \in(0, \underline{h}]$, with 0 representing 'no policy', and $\Xi=\underline{\mathrm{h}}$ representing 'full flexibility'.

In line with the German STW policy, the government replaces a fraction $\tau_{\Xi}$ of the regular full time wage of workers with $h<\underline{\mathrm{h}}$. For each worker on STW the government pays $\tau_{\Xi} \cdot(\underline{\mathrm{h}}-h) \omega(\underline{\mathrm{h}}, \varepsilon, n)$. This is financed through a lump-sum tax $\tau$ on all workers to balance the government's budget. There is no experience rating and thus no direct charge to firms for workers being compensated under this scheme.

The size of the labor force is $L$. The government's budget constraint is given by

$$
L \cdot \tau=\tau_{\Xi} \cdot \int_{s=\left(\varepsilon, n_{-1}\right)}(\underline{\mathrm{h}}-h) \cdot \mathbb{1}_{h} \omega(\underline{\mathrm{h}}, \varepsilon, n) \lambda(d s)
$$

The indicator $\mathbb{1}_{h}$ takes the value of one if $\underline{\mathrm{h}}>h \geq \underline{\mathrm{h}}-\Xi$. When the policy is not in place $\tau_{\Xi}=0$. Since the policy is financed in a lump-sum fashion, taxes do not affect the negotiation because they do not change a worker's surplus from finding a match. The value of employment becomes

$$
W^{e}(\varepsilon, n)=\omega(h, \varepsilon, n) \cdot h+\tau_{\Xi} \cdot(\underline{\mathrm{h}}-h) \omega(\underline{\mathrm{h}}, \varepsilon, n)-\xi(h)-\tau+\beta \mathbb{E}_{\varepsilon^{\prime} \mid \varepsilon}\left[s W^{u}+(1-s) W^{e}\left(\varepsilon^{\prime}, n^{\prime}\right)\right] .
$$

\footnotetext{
${ }^{15}$ Below, we show the robustness of our results with respect to $\underline{h}$ due to additional flexibility in hours (working-time accounts as stressed by Burda and Hunt (2011)) or contractual arrangements (Dustmann et al. (2014).
} 
The optimal hours policy as a function of $\Xi$ becomes

$$
h^{*}=\max \left\{\underline{\mathrm{h}}-\Xi,\left[\frac{\varepsilon \alpha n^{\alpha-1}}{\xi^{\prime}\left(h^{*}\right)(1-\eta(1-\alpha))}\right]^{\frac{1}{1-\alpha}}\right\} .
$$

This defines $\mathcal{H}(\varepsilon, n ; \Xi)$. The employment function characterized above is not changed by the policy.

Importantly, the wage function specified in $(8)$ is assumed not to respond to the use of STW by a firm. That is, workers in firms using STW work fewer hours and receive a wage according to (8), but we prevent the firm from appropriating part of the workers' surplus that comes from the government subsidy. We justify this assumption both on the grounds of empirical relevance and its quantitative implications.

In our model, if wages were renegotiated after accounting for the subsidy to workers, firms would capture a fraction of the government subsidy and be induced to increase employment 16 Using STW to reduce hours and increase employment in this manner is contrary to both the stated intent of the policy and evidence of firm behavior during the use of STW 17

\section{Calibration and Estimation}

This section presents our parameter values. The model is fit to the economy prior to the policy intervention and is then used to explore the effects of STW.

\subsection{Parameterization}

The stationary model is fit to the German economy prior to the 2009 recession. There is an hours constraint $\underline{\mathrm{h}}>0$ but no STW policy, i.e. $\Xi=0$. The model is solved at a monthly frequency. The discount factor is set at $\beta=0.9967$, corresponding to an annual interest rate of $4 \%$.

The top block of Table 2 indicates the calibrated parameters. The matching function is assumed to be of the form $M=\mu U^{\gamma} V^{1-\gamma}$. We set the match elasticity to $\gamma=0.65$ as in Kohlbrecher, Merkl, and Nordmeier (2016). We target the German monthly job-finding probability of $\phi=0.0622$ as reported in Ravenna and Schott (2016). The German Employment Agency publishes a monthly series of the number of vacancies. We find an average labor market tightness of $\theta=0.091$. This implies that in the steady state $\mu=0.1439$. The resulting monthly vacancy-filling probability is $q=0.6835$. The parameter $\alpha$, which governs the decreasing returns to scale in production, is taken from Cooper et al. (2007) and set to $0.65{ }^{18}$ Workers' disutility of labor is given by $\xi(h)=\xi_{0} h^{1+\frac{1}{\xi_{1}}}$

The parameters $b, \xi_{0}$, and $\eta$ are jointly calibrated by targeting average employment, average hours worked, and the labor share. From the German micro data we obtain a target for the average establishment size of

\footnotetext{
${ }^{16}$ This leads to the existence of a second local maximum in the firm's objective function, one where $h<\underline{\mathrm{h}}$, and another for $h \geq \underline{\mathrm{h}}$. Because the subsidy $\tau_{\Xi}$ is large $(60-67 \%)$, this has the quantitative implication that all firms end up using STW, while simultaneously expanding their number of employees. The most closely related paper studying the use of STW in Germany, Balleer et al. (2016), circumvents this problem by having single-worker firms.

${ }^{1 \top}$ See e.g. Burda and Hunt (2011) p. 303, Cahuc and Carcillo (2011), Boeri and Bruecker (2011), Tijdens, van Klaveren, Bispinck, Dribbusch, and Öz (2014) and Engbom, Detragiache, and Raei (2015).

${ }^{10}$ Our data does not allow us to estimate the parameter $\alpha$ directly from the German plant-level data. The estimates in Bachmann and Bayer (2014) for a cross-section of German non-financial firms implies a value of $\alpha=0.7$.
} 


\begin{tabular}{c|c|c|c}
\hline \hline Parameter & Meaning & Value & Reason \\
\hline \multicolumn{3}{c}{ Calibrated } \\
$\beta$ & Discount factor & .9967 & Annual $r=4 \%$ \\
$\gamma$ & Matching elasticity & .65 & Kohlbrecher et al. $(2016)$ \\
$\mu$ & Matching efficiency & .1439 & $\theta=0.091$ \\
$\alpha$ & $F(L)=L^{\alpha}$ & .65 & Cooper et al. $(2007)$ \\
$\bar{\varepsilon}$ & Mean of $\varepsilon$ & 1 & Normalization \\
$b$ & Flow Value Unemployment & .025 & Average employment =98.5 \\
$\xi_{0}$ & Disutility of work (scale) & .123 & Average hours $=1$ \\
$\eta$ & Worker bargaining power & .413 & Labor share 0.76 (OECD) \\
\hline \multicolumn{2}{|c}{ Estimated } & Table 3 \\
$\xi_{1}$ & Disutility of work & 4.15 & Table 3 \\
$c_{v}$ & Vacancy cost & .071 & Table 3 \\
$\rho_{\varepsilon}$ & Persistence of $\varepsilon$ & .983 & Table 3 \\
$\sigma_{\varepsilon}$ & Std. dev. of $\varepsilon$ & .039 & \\
\hline
\end{tabular}

Table 2: Model Parameters.

98.5 workers. As in Cooper et al. (2007) we normalize hours such that in the steady state without time-varying $\varepsilon$, average hours are equal to one. We calibrate $\eta$ by targeting the labor share in manufacturing in Germany between 1995-2008, which is 0.76 . The flow value of unemployment $b$ amounts to $13.8 \%$ of average monthly wages.

The remaining parameters are estimated via simulated method of moments (SMM). These parameters are the vacancy-posting $\operatorname{costs} c_{v}$, the disutility of labor $\xi_{1}$, and the parameters governing the evolution of idiosyncratic productivity shocks, $\rho_{\varepsilon}$ and $\sigma_{\varepsilon}$. There exists no one-to-one mapping of parameters into moments here. We therefore choose moments that are informative about the underlying parameters. The estimated parameter values are shown in Table 2. The estimation is summarized in Table 3 ,

\begin{tabular}{c|c|c|}
\hline \hline Moment & Data & Model \\
\hline$\frac{L-N}{L}=\frac{\delta}{\phi+\delta}$ & .09 & .09 \\
$\Delta h<|5 \%|$ (annual) & .538 & .542 \\
$\Delta n<|5 \%|$ (annual) & .476 & .485 \\
$c v(n) / c v(h)$ & 5.63 & 5.77 \\
\hline Distance $L(\Theta)$ & - & $1.395 \%$ \\
\hline
\end{tabular}

Table 3: Data and Model Moments

A key consistency requirement is that the stock and flow concepts of unemployment consistently yield an unemployment rate of $9.04 \%$, the average unemployment rate in Germany between 1992 and 2009, the same period that was used to compute labor market tightness ${ }^{19}$ The jointly estimated parameters must ensure that this consistency requirement is met.

The hours change distribution is informative about the parameter $\xi_{1}$. It influences how firms adjust hours

\footnotetext{
${ }^{19}$ The law of motion for unemployment implies that $u^{*}=\frac{\delta}{\phi+\delta}$, where $\delta$ is the job destruction rate. The stock of unemployed is given by firms' employment policy, pinning down total employment $N$, which is $L\left(1-u^{*}\right)$.
} 
following a change in $\varepsilon$. We target the fraction of firms with small hours adjustments 20 This inactivity rate is equal to $53.8 \%$. Similarly, we identify $c_{v}$ via the fraction of employment inactivity (47.6\%). Another moment we include in the estimation is $\frac{c v(n)}{c v(h)}$, the ratio of the cross-sectional coefficients of variation of employment and hours. This moment is informative about the relative importance of the hours and employment margins in the economy's steady state.

The estimation finds the vector of parameters $\Theta=\left(c_{v}, \xi_{1}, \rho_{\varepsilon}, \sigma_{\varepsilon}\right)$ that minimizes the (weighted) distance between moments calculated from the model and the data. This distance is denoted as $L(\Theta)$.

\subsection{Moments}

The estimated parameters generate simulated moments that lie close to their empirical counterparts, as Table 3 shows. The size of the vacancy posting $\operatorname{costs} c_{v}$ implies that firms spend on average $1.2 \%$ of monthly profits on vacancy posting costs ${ }^{21}$ The estimated values of $\rho_{\varepsilon}$ and $\sigma_{\varepsilon}$, as well as the steady state job destruction rate lie close to parameter values estimated in related studies 22

The model generates an inactivity rate in hours of $54.2 \%$ and an hours change distribution which is very close to the data. The model's employment change distribution is characterized by a large inactivity region of $48.5 \%$, which is slightly above its empirical counterpart 23 While the model produces a realistic employment change distribution, the absence of a richer structure of employment adjustment costs implies that the model produces too many large adjustments and too few small adjustments compared to the data.

An important object in determining the model's dynamics is the negotiated hourly wage between workers and firms. This is shown in Figure 5. The hourly wage is decreasing in the total number of employees $n$ and the number of hours $h$. If $n$ increases for a given $h$, this decreases the marginal product of labor and thus negatively affects the wage. When changing hours there are two effects at work. First, similarly to the case for changes in $n$, for a given $n$ an increase in $h$ decreases the marginal product of labor. This negatively affects the wage. However, the wage now also takes the worker's disutility for providing hours into account. As hours increase, this disutility effect becomes increasingly stronger.

More productive firms are larger. The model also generates a positive relationship between the intensive and extensive margins of employment, workers and average hours. Large firms choose longer hours for their workers. The reason behind this has to do with labor hoarding: the presence of labor adjustment costs generates inactivity in the firm's employment policy. Facing the possibility of receiving a low idiosyncratic productivity shock, a large firm might find it optimal to be able to reduce total hours worked $(n \cdot h)$ through a reduction in hours. This positive relationship between $n$ and $h$ generates a positive relationship between firm size and hourly wages.

\footnotetext{
${ }^{20} \mathrm{As}$ in the data we define 'inactivity' as adjustments smaller than $5 \%$ in absolute value. To correspond to our data equivalent, we use time-aggregation to compute year-to-year changes.

${ }^{21}$ Cooper et al. (2007) find that total monthly adjustment costs are $0.775 \%$ of firm profits. Silva and Toledo (2009) find that the labor costs of posting vacancies are $32.66 \%$ of the average monthly worker wage. In our model this figure is $39.18 \%$.

${ }^{22}$ For example, we obtain a job destruction rate $\delta=0.0062$, which is very close to the value of 0.00605 obtained by Ravenna and Schott (2016) using German worker-level data. The estimated baseline values in Bachmann and Bayer (2014) imply monthly values of $\rho_{\varepsilon}=.99725$ and $\sigma_{\varepsilon}=0.0261$.

${ }^{23}$ This is shown Figures 18 and 19 in the Appendix.
} 


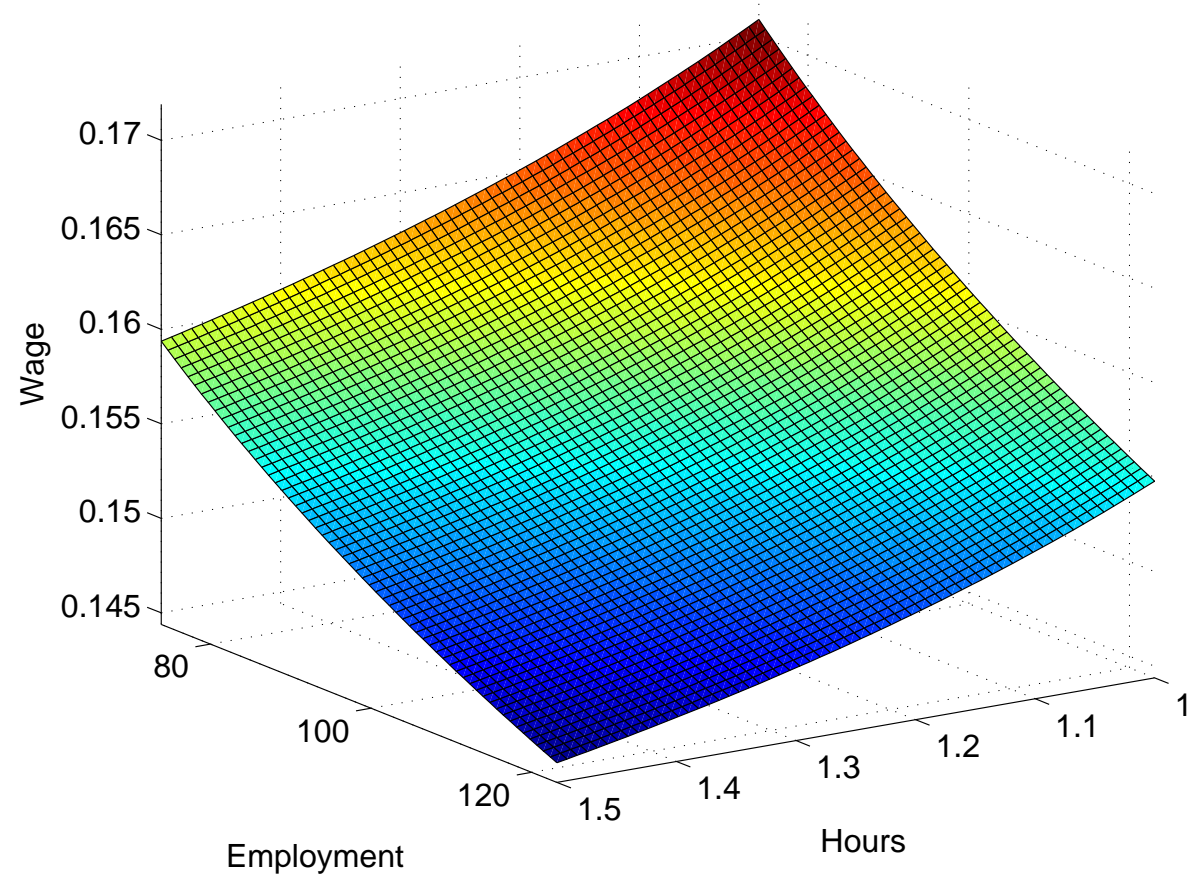

Figure 5: Hourly Wage

Hourly wage as a function of hours and employment when $\varepsilon$ is equal to its unconditional mean.

\section{$5 \quad$ Policy Implications and Aggregate Shocks}

We now add two exogenous aggregate states to the model. The first one is an aggregate productivity shock $A$. The second one is the STW policy. There are two levels of aggregate productivity, $A^{\text {low }}$ and $A^{\text {high }}$. In a recession, i.e. when $A=A^{\text {low }}$, the STW policy can be active or not. The state when STW is active during a recession is denoted as $A^{\Xi}$. The three aggregate states are therefore $\left\{A^{\text {high }}, A^{\text {low }}, A^{\Xi}\right\}$. We assume that STW is always unexpected by firms ${ }^{24}$ The joint transition matrix $\Pi$ of the aggregate state between periods $t$ and $t+1$ is given by

$$
\Pi=A_{A^{\text {low }}}^{A^{\text {high }}}\left(\begin{array}{ccc}
A^{\text {high }} & A^{\text {low }} & A^{\Xi} \\
1-\rho & 1-\rho & 0 \\
1-\rho & \rho-\pi & 0
\end{array}\right) .
$$

The probability of a change in the productivity state absent STW is given by $\rho$. Once the economy is in the STW-recession state $A^{\Xi}$, the policy will continue with probability $\pi$. The probability of entering the high productivity state is not affected by the STW policy. The probability $\pi$ is chosen to generate an expected

\footnotetext{
${ }^{24}$ As a robustness exercise we compute results when the policy is not unexpected in Section 6 . The results are qualitatively unchanged.
} 
duration of STW of six months ${ }^{25}$ We calibrate $\rho$ to generate an average duration of a recession and expansion of three years.

With shocks to aggregate productivity $A$ the vacancy-filling probability is no longer time-invariant. Firms need to forecast the vacancy-filling probability $q$, which is an equilibrium object determined by $\lambda\left(\varepsilon, n_{-1}\right)$, the joint distribution of firms' productivity and employment levels. To solve the model with aggregate variation we employ a computational strategy along the lines of Krusell and Smith (1998). To forecast $q^{\prime}$ firms use the information about current $q$ and the current and expected aggregate productivity levels. The outcome of this iterative procedure is a forecasting equation used by firms given by

$$
\log \left(q^{\prime}\right)=\beta_{0}+\beta_{1} \log (q)+\beta_{2} A+\beta_{3} A^{\prime}+\beta_{4}\left(A=A^{\prime}\right)+\nu
$$

The estimated coefficients when $A^{\text {high }}=1, A^{\text {low }}=0.99$, and $\rho=.0904$ are $\beta_{0}=1.13, \beta_{1}=0.62, \beta_{2}=2.32, \beta_{3}=$ -3.59 , and $\beta_{4}=0.01$. The resulting $R^{2}=0.9991$ and the maximum accumulated forecast error is $0.15 \%$. The fact that firm policy functions are characterized by a region of inactivity facilitates the estimation of the forecast equation. For a given $q$, shocks to aggregate productivity generate shifts in the firms' inactivity regions. The vacancy-filling probability $q$ is a slow-moving state variable because of the persistent idiosyncratic shocks, which generate a staggered adjustment process of labor demand. How many firms have adjusted labor demand is reflected in the aggregate statistic $q$. Therefore current $q$ is an important variable in forecasting $q^{\prime}$. We then solve the firm's and worker's optimization problem with the transition matrix $\Pi$ and the forecast law of motion for $q^{\prime}$ supplementing the idiosyncratic shocks, i.e. the firm's state becomes $s=\left(\varepsilon, n_{-1} ; A, q\right)$.

\subsection{STW without Aggregate Productivity Shocks}

We are ultimately interested in assessing the effectiveness of the German STW policy during the recent recession. To begin, we consider the effects of STW without variations in aggregate productivity. This allows us to isolate the effect of the policy and later study potential interactions with aggregate productivity.

A key implication of the constraint is that if a firm cannot choose $h<\underline{\mathrm{h}}$ after receiving a negative shock to idiosyncratic productivity, it will make additional adjustments in labor demand via the extensive margin. The STW policy gives the firm additional flexibility in hours. This flexibility implies fewer layoffs and a lower unemployment rate. Because of its effect on the vacancy-filling rate, the lower unemployment rate leads to higher search costs for expanding firms that wish to hire new workers. This misallocation will produce a negative effect on output.

The direct effect of the policy is to eliminate the floor on hours. Figure 6 shows the cumulative distribution of average hours worked with and without STW. Without the constraint a significant fraction of firms chooses $h<\underline{\mathrm{h}}$. Absent the policy, firms create an hours buffer in order to be able to respond to variations in $\varepsilon$ without having to resort to firing.

Next, we show a simulation of the transition from an economy with a binding hours floor to one where STW is in place. This is represented by the blue, solid lines in Figure 7. This case is labeled 'GE' for 'general equilibrium', because the vacancy-filling probability $q$ endogenously responds to changes in firms' policies. Figure

\footnotetext{
${ }^{25}$ This corresponds to $\pi=.8706$. The maximum duration of STW was six months before the 2009 episode. During 2009 the maximum duration was increased to 24 months.
} 


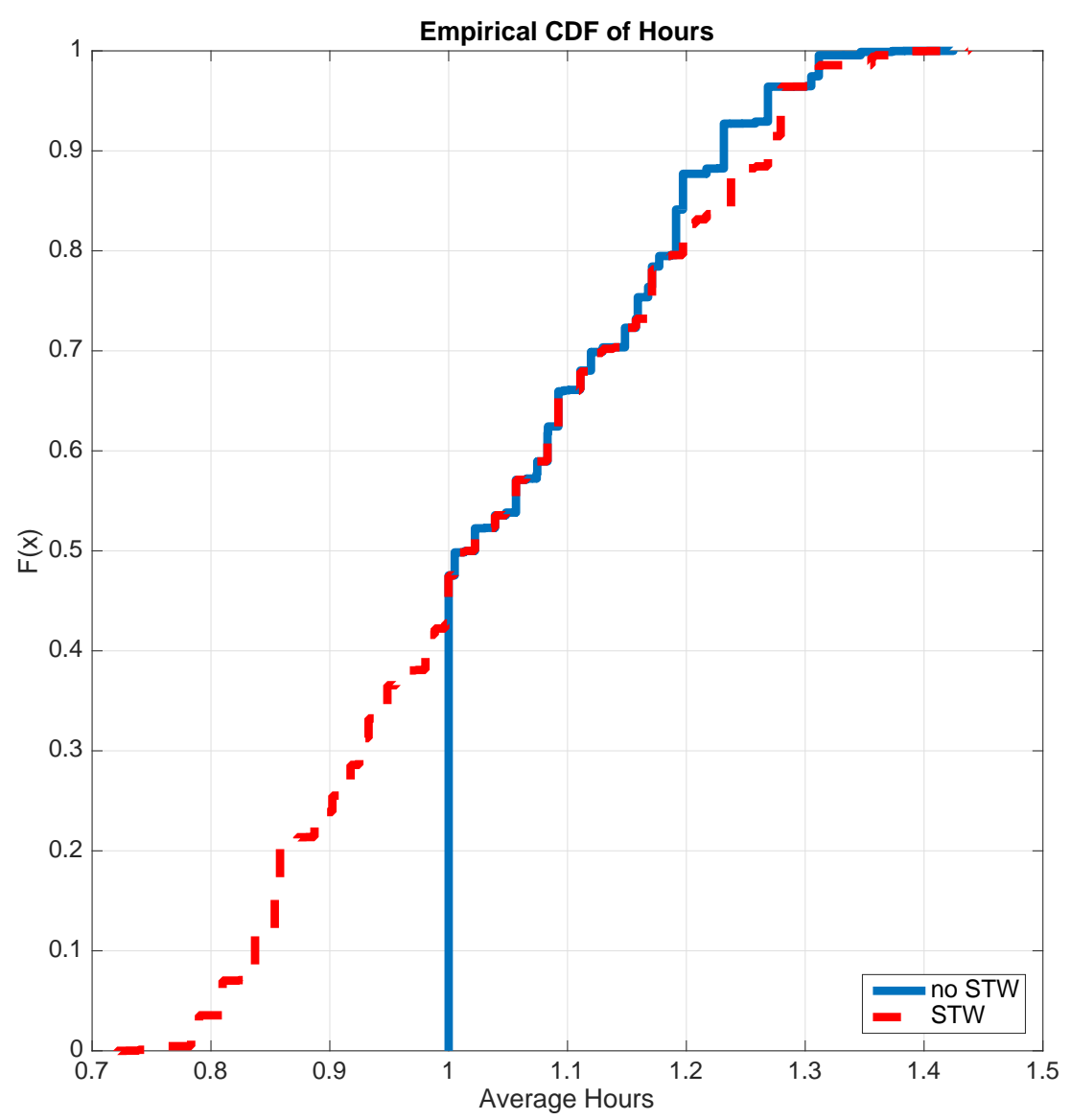

Figure 6: CDF of Average Hours

Empirical cumulative density function of average hours worked with and without STW.

7 shows that under the STW policy employment increases by $2.5 \%$ (the unemployment rate falls to $75 \%$ of the steady state unemployment rate without STW). Average hours worked decline by $4.5 \%$, leading total hours worked to decrease. The vacancy-filling probability decreases by 4.3 percentage points, implying an increase in vacancy-creation costs of $6.65 \%$. This leads to less hiring by expanding firms, causing the observed drop in output of $1.05 \%$.

The endogeneity of $q$ is crucial for the negative effect on output. The red, dashed lines in Figure 7 show the results for the transition into an economy with STW when $q$ is exogenously fixed at its steady-steady value. This is abbreviated as 'PE', for 'partial equilibrium'. The positive employment response is now more than twice as large. Importantly, when firms do not face higher vacancy-creation costs as a result of the policy, total output is virtually unaffected ${ }^{26}$ In partial equilibrium, the policy increases employment without the negative consequences for output.

To reinforce this point, consider the effects of the policy on average hours and employment growth for

\footnotetext{
${ }^{26}$ Additional negative effects on total hours worked $(n \cdot h)$ come from the increase in wages.
} 

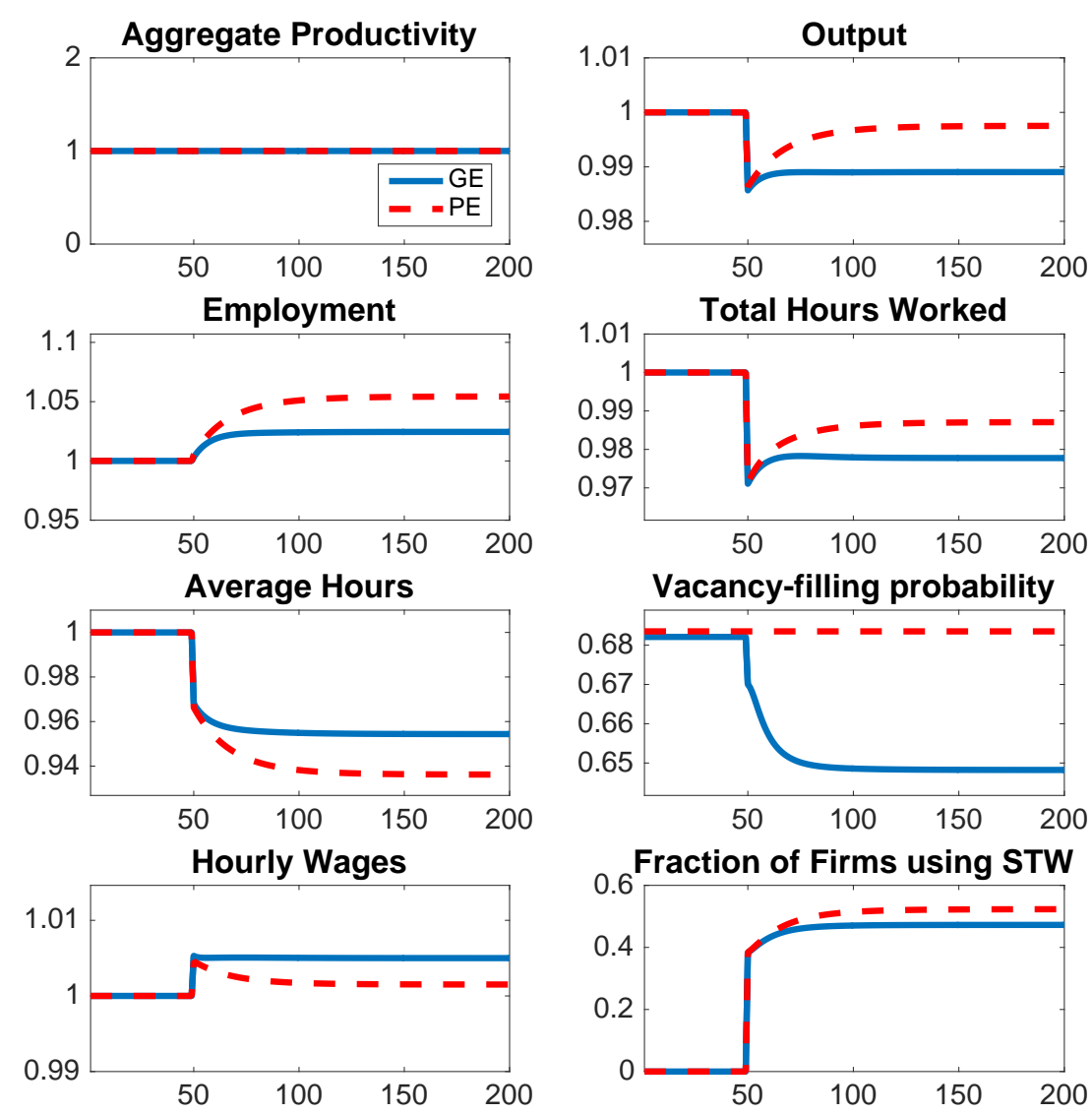

Figure 7: STW under PE and GE

Transition paths for an economy with no STW policy and an active STW policy. The solid blue line shows results for the economy in general equilibrium (endogenous $q$ ), the red-dashed line shows the partial equilibrium (exogenous $q$ ) case. The x-axis shows time. The STW policy is activated in period 50 .

different types of firms. We group firms into four bins, based on their idiosyncratic productivity and lagged employment level in relation to the respective median. We focus attention on two groups here: Firms with low $\varepsilon$ and high $n$ and firms with high $\varepsilon$ and low $n$. Figure 8 compares the responses of average hours worked and average employment for these groups at the time the STW policy becomes active. The left (right) side shows the response for firms with low (high) $\varepsilon$ and high (low) employment. The top (bottom) panel shows the response of average hours (employment). As before, the solid blue line shows the results in general equilibrium, while the red dashed line shows the partial equilibrium responses, when $q$ is held constant.

The figure shows the heterogeneous response of firms. Firms with low $\varepsilon$ and high $n$ will tend to shrink. These are the firms that are actively using the STW policy. When the policy is not in place, the hours floor is binding for these firms. After the introduction of STW, they reduce average hours worked to a level below $\underline{h}$ and employ more workers because there are fewer layoffs. The responses are qualitatively similar under exogenous 

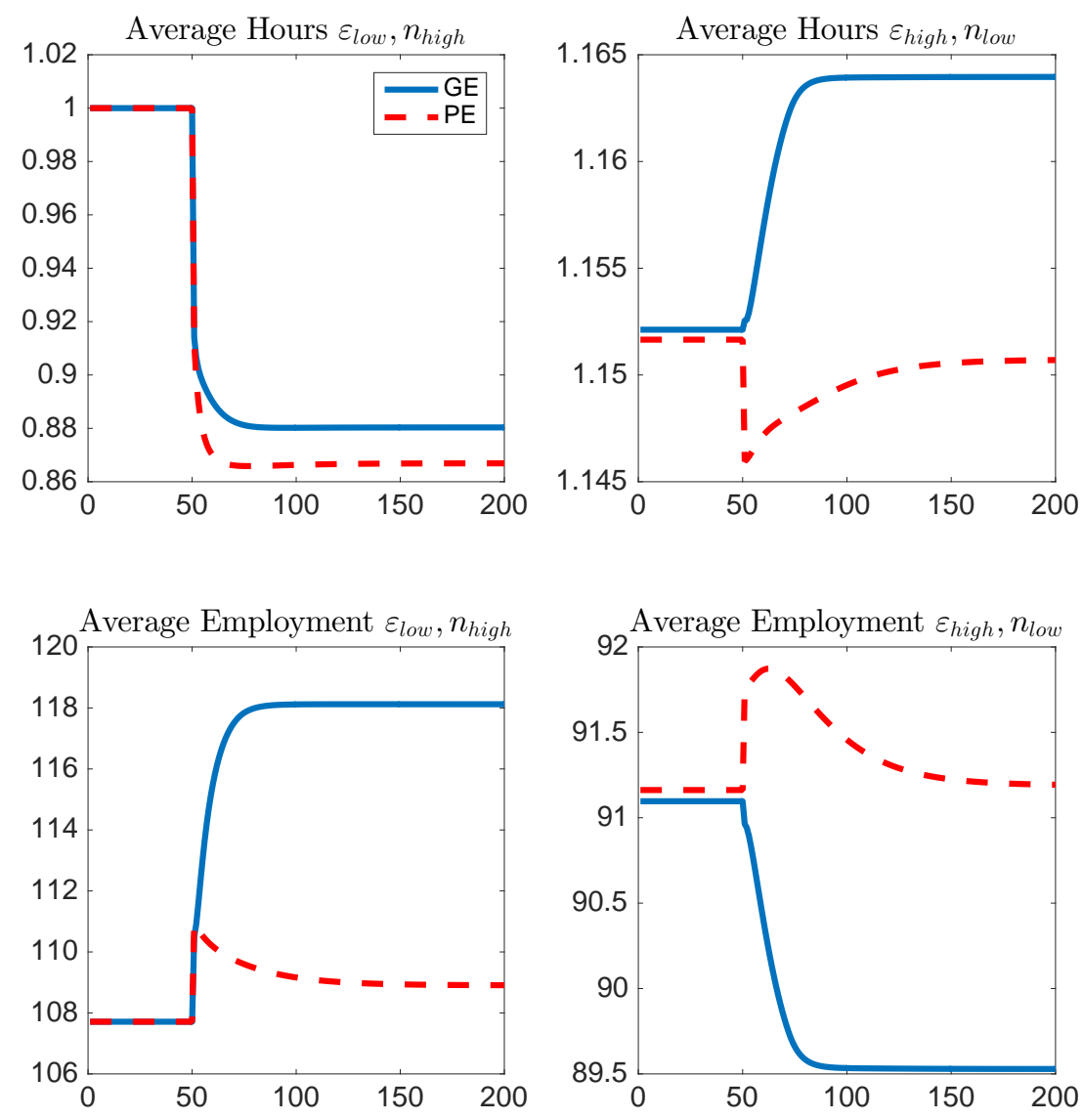

Figure 8: Average Hours and Average Employment

Average Hours and Average Employment for firms with low (high) $\varepsilon$ and high (low) values of lagged employment, $n$. The x-axis shows time, the y-axis respectively shows average hours and employment. At $t=50$ the STW policy is introduced.

or endogenous $q$. When $q$ responds to the STW policy and hiring costs increase, retaining more workers inside the firm becomes more attractive and the positive employment effects are larger.

Contrast this with the behavior of firms with high $\varepsilon$ and low $n$. These firms tend to grow and are therefore generally not using the STW policy. Here the differences between the exogenous and endogenous $q$ cases stand out clearly. While under exogenous $q$ growing firms shift total labor demand towards slightly fewer average hours and more employment as a result of the additional flexibility, the opposite is the case when $q$ endogenously responds. In that case, because of the increase in vacancy creation costs $\frac{c_{v}}{q}$, growing firms hire fewer workers and instead work their existing workers longer hours.

The STW policy creates additional flexibility at the firm-level by making it possible for firms to overcome the hours variation friction. This exerts positive productivity effects because firms set hours such that the static first-order-condition (10) always holds. On the other hand the policy leads to less employment growth in expanding firms. Because more labor is being retained at unproductive shrinking firms, expanding firms 
are faced with a higher vacancy creation cost. This leads to less employment growth in firms with positive productivity growth, which negatively affects output. As Figure 7 shows, the joint effect of these two forces is that employment increases but output falls.

\section{$5.2 \quad$ STW during Recessions}
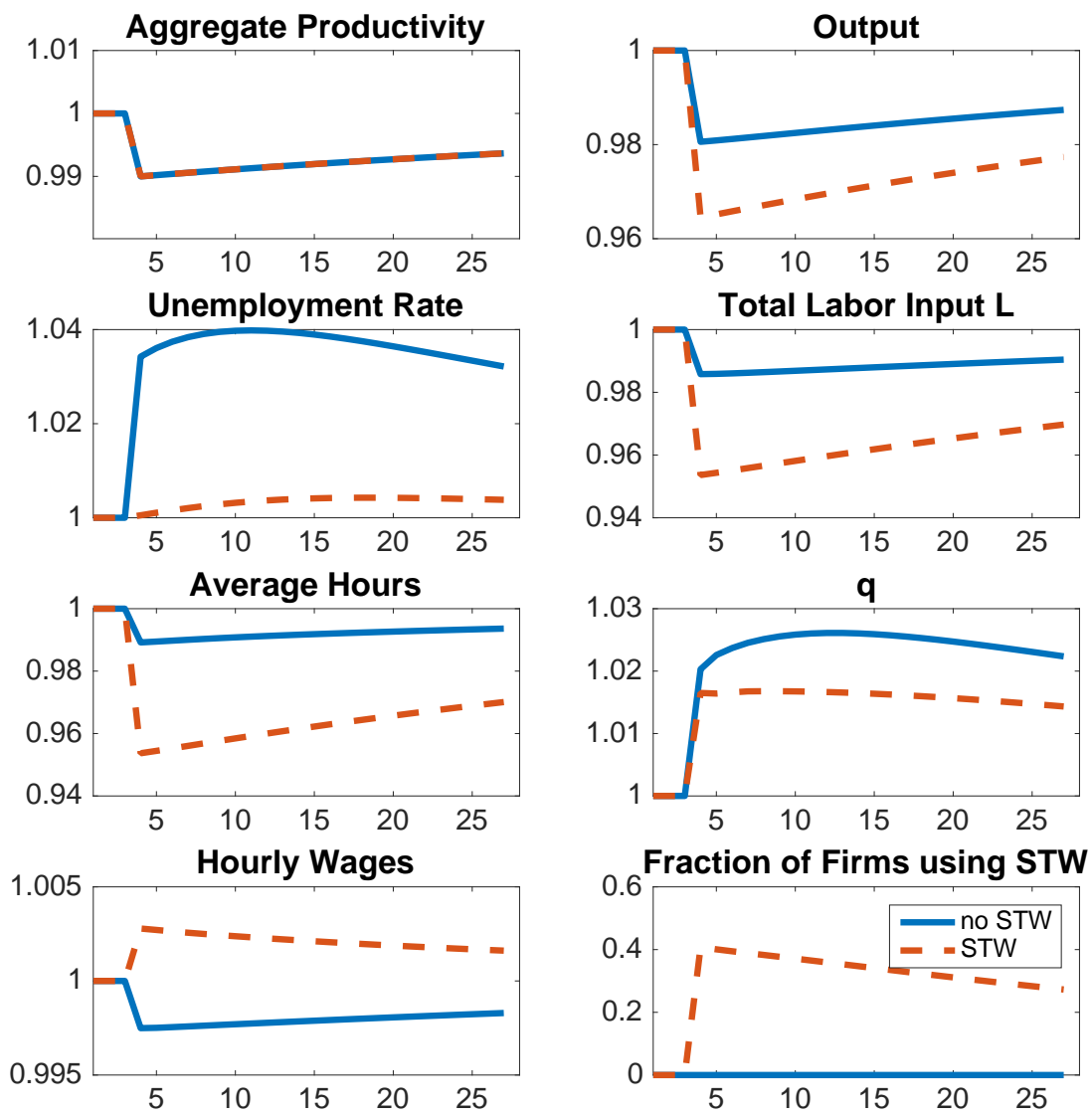

Figure 9: Impulse Response Functions

The solid blue (dashed red) lines show a recession without (with) STW in place. All values with the exception of the fraction of firms using STW (last panel) have been normalized to their pre-shock values.

We now show how the STW policy interacts with negative productivity shocks. We set $A^{\text {low }}=A^{\Xi}<1$ to generate two recession states, one with, and one without the policy. Figure 9 shows two sets of impulse response functions. Starting in $A^{\text {high }}$ the solid blue (red dashed) line shows the response of an economy experiencing a one-time productivity shock $A^{\text {low }}\left(A^{\Xi}\right)$. Following the negative productivity shock, firms demand less labor, as shown by the decrease in total labor input. The composition of this reduction is very different across the two recessions. Absent the policy, the hours floor is binding and only small reductions in average hours are feasible. Consequently, the number of employees falls and the unemployment rate rises.

When the policy is in place, firms reduce average hours by much more while retaining a larger fraction of 
their employees. The result is that under the policy, the unemployment rate increases by $0.5 \%$, compared to an increase of $4 \%$ without the policy. As the top right panel of Figure 9 shows, the decline in output is stronger when the policy is in place. During the STW policy, output falls by an additional $1.6 \%$ of pre-recession output.

This is a 'cleansing' effect of recessions, brought about by the endogenous vacancy filling rate. Inflows into unemployment lead to an increase in $q$. This incentivizes job creation and is the reason why recessions can lead to labor reallocation that can ultimately be productivity-enhancing. With the STW policy the 'cleansing' channel is muted. As shown above, this implies that growing firms hire less labor. In recessions without the policy, the correlation of plant-level productivity and employment increases, while with the STW policy the correlation declines (see Figure 10). Every time a firm decides to hold on to a worker instead of releasing him or her into the pool of unemployed, the firm inadvertently decreases the vacancy-filling probability for all other firms. The individual firm does not take this externality into account when making its optimal employment decision.

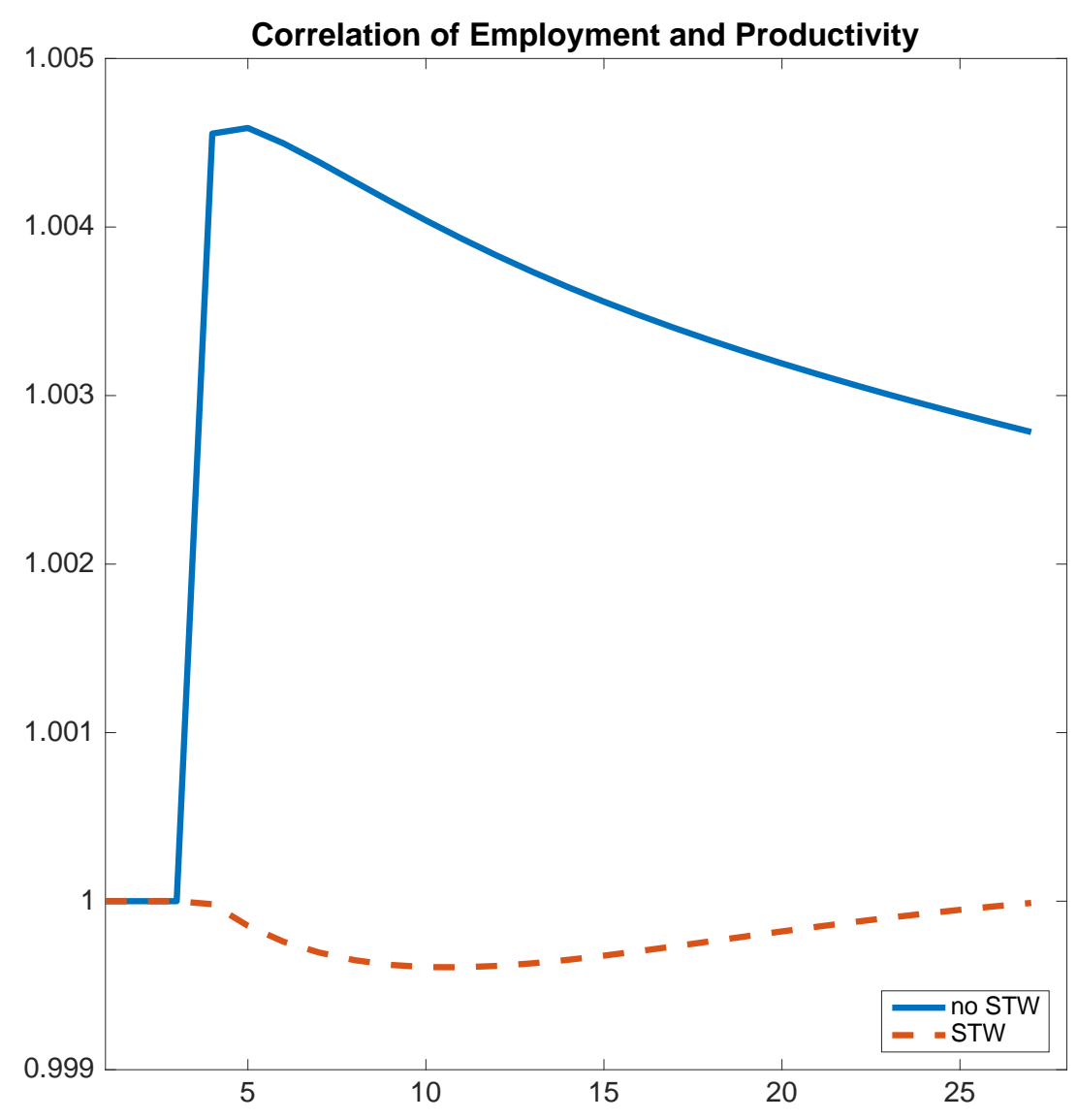

Figure 10: Productivity-Employment Correlation

Cross-sectional correlation between productivity and employment. The correlation in good times has been normalized to one.

To provide more details on the implication of the correlation between productivity and employment, consider 
Figure 11, where we show average labor productivity per worker and per hour. The effect of the policy is a relative decrease in ALP per worker, while ALP per hour increases. Because of the reduction in average hours worked, labor productivity per worker falls by more when the policy is in place. However, because of decreasing returns, the "marginal hour" of work now produces more output, causing labor productivity per hour to increase.
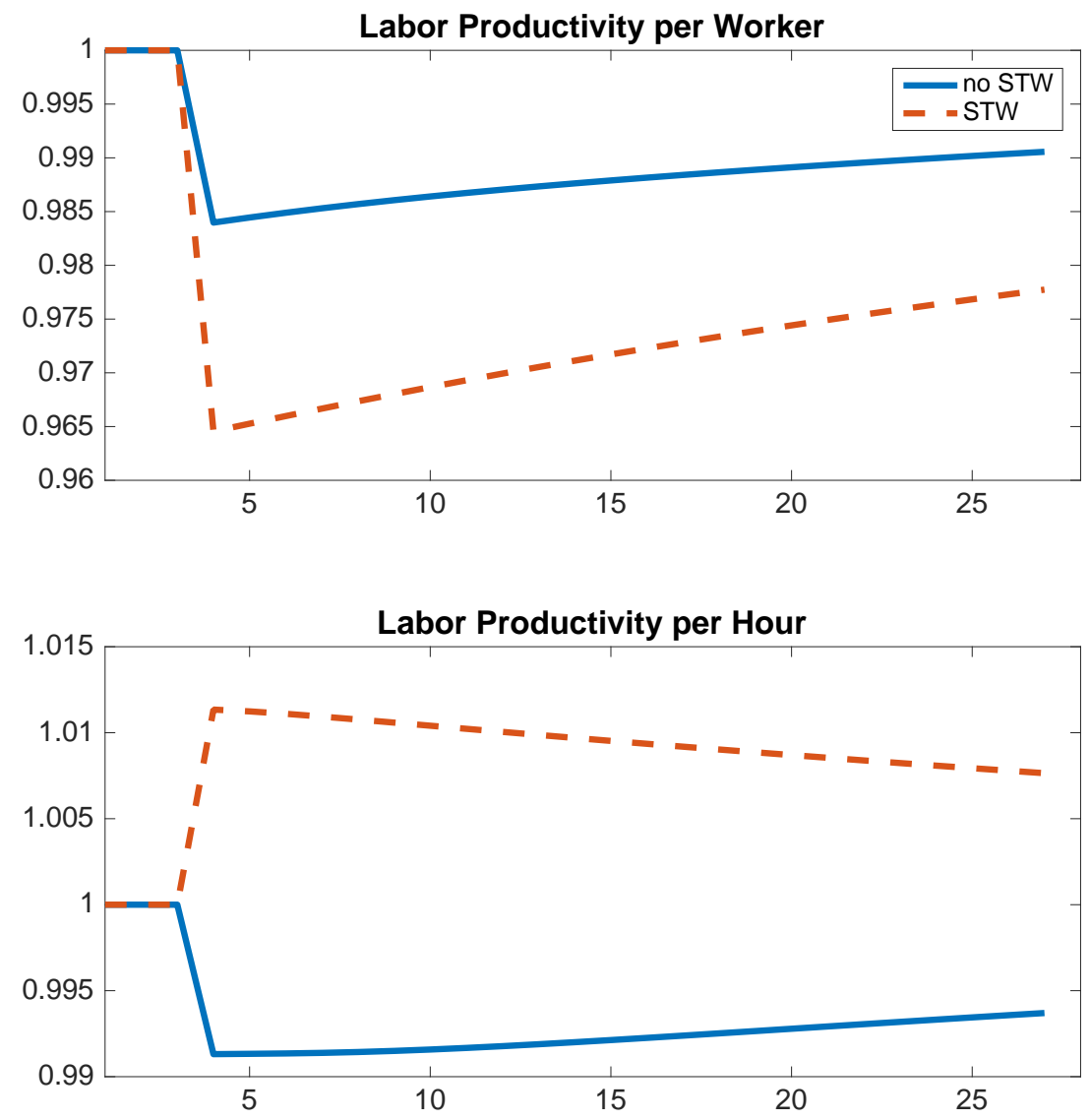

Figure 11: Average Labor Productivity

The top (bottom) panel shows average labor productivity (ALP) per Hour (Worker). The ALP prior to the shock has been normalized to one.

On the aggregate level, the STW policy decreases both job destruction and job creation, as we show in Figure 12. The recession without STW leads to a large spike in job destruction. Employment falls mainly due to inflows into unemployment. Job creation declines on impact but then overshoots. The reason for the overshooting is that after the initial employment adjustment it becomes cheaper for firms to create jobs because the vacancy-filling probability $q$ rises.

The STW policy can prevent an increase in job destruction during a recession. But because fewer workers are released into the pool of the unemployed, the vacancy-filling probability increases by less, dampening the incentives for job creation. 

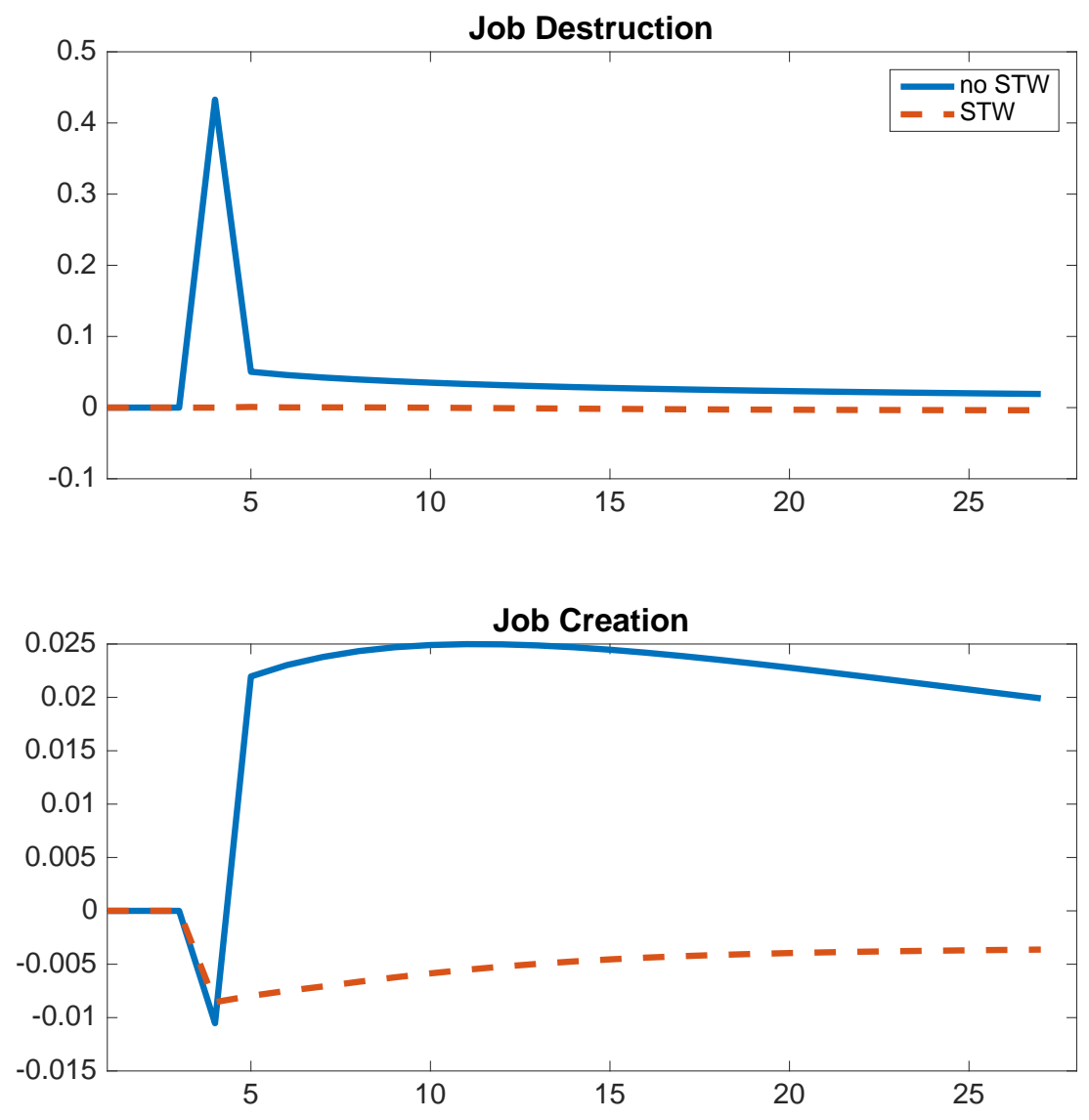

Figure 12: Job Destruction and Job Creation

The solid blue (dashed red) lines show a recession without (with) STW in place. Both series are shown in log deviations from their values in steady state.

\section{Discussion}

In this section we discuss the robustness of our results and take the model's conclusion to the data.

\subsection{Robustness}

We provide some robustness results of the key effects of the STW policy with respect to parameter changes. We summarize the effects of the STW policy on employment and output in $D_{N}$ and $D_{Y}$. They give the maximum absolute difference of employment and output during a recession with or without the STW policy in place. For variable $x$ we let $S\left(S^{\Xi}\right)$ be the series of observations following the negative productivity shock. Then $D_{x}=\max \left|S-S^{\Xi}\right|$. To evaluate the elasticities that follow, in our benchmark model the employment difference is $D_{N}=0.37 \%$ and the output difference is $D_{Y}=-1.61 \%$.

We start by examining the importance of the models' parameters for the size of the employment and output differences. We show the elasticities of $D_{N}$ and $D_{Y}$ with respect to parameter changes in Table 4 . These 
elasticities are informative about which parameters are important in driving the key channels in our model. They are computed by changing a parameter and then letting the economy converge to its new steady state without aggregate productivity shocks $\sqrt{27}$ We then add aggregate shocks to compute impulse response functions and obtain the employment and output differences following a recession with or without STW.

\begin{tabular}{c|c|c|}
\hline \hline Model & $D_{N}$ & $D_{Y}$ \\
\hline$b$ & -0.23 & -2.23 \\
$\eta$ & -0.36 & -3.06 \\
$c_{v}$ & 1.44 & -0.86 \\
$\rho_{\varepsilon}$ & -32.85 & -35.64 \\
$\sigma_{\varepsilon}$ & 0.07 & -1.29 \\
$\xi_{0}$ & 9.50 & 8.42 \\
$\xi_{1}$ & 3.31 & -4.76 \\
\hline
\end{tabular}

Table 4: Elasticities of $D_{x}$ The table shows the elasticities of $D_{x}$ with respect to changes in model parameters. $D_{x}=\max \mid S-$ $S^{\Xi}$, where $x$ is respectively employment $(\mathrm{N})$ and output $(\mathrm{Y}) . S$ and $S^{\Xi}$ denote the series of $N$ observations following a recession with (without) STW.

Table 4 shows that the parameters $b, \eta, c_{v}$, and $\sigma$ have relatively small effects on the size of the employment and output differences between STW and a normal recession. For example, a $1 \%$ increase in workers' bargaining power $\eta$ leads to a $0.36 \%$ smaller $D_{N}$ and a $3.06 \%$ smaller $D_{Y}$ relative to the benchmark. As workers appropriate a larger fraction of the match surplus, the firms react less to changes in aggregate conditions. The same intuition applies to increases in $b$, which raise workers' outside option. Small changes in $\sigma$ do not affect most firms' regions of inactivity, therefore leading to small effects on the main channels of the model. The parameter $\rho_{\varepsilon}$ denotes the persistence of idiosyncratic shocks and generates the largest elasticities of $D_{N}$ and $D_{Y}$. An increase in $\rho_{\varepsilon}$ leads to larger regions of inactivity and more inaction in firms' hours and employment policy functions. A recession therefore leads to smaller employment and output adjustments and the STW policy becomes less effective. The parameters governing the workers' disutility of labor, $\xi_{0}$ and $\xi_{1}$ are key determinants of the hourly wage equation (8). Increase in $\xi_{0}$ and $\xi_{1}$ increases the hourly wage and change the trade-off between hours and employment. For example, increasing $\xi_{1}$ incentivizes firms to grow by expanding the workforce, rather than using overtime. Similarly, during a recession, firms tend to decrease labor demand through hours reductions, which become more feasible during STW, increasing $D_{N}$ relative to the baseline. Because fewer of the changes in labor demand come from changes in the number of employees, the effect on $q$ is limited and the output effects of the policy are smaller.

Next, we show the robustness of our results under alternative specifications of the policy. Table 5 summarizes our findings. The first row shows the benchmark model. In Row 2 we study the impact of the lower bound for hours. If $\underline{\mathrm{h}}<1$, firms can reduce hours below 1 even in the absence of STW, giving them additional flexibly compared to the benchmark model. This is in the spirit of the working time accounts emphasized in Burda and Hunt (2011). To show the sensitivity of our results we consider $\underline{h}=0.97528$ While the results remain qualitatively unchanged, fewer firms now use the policy during a recession. As a result the relative reduction in

\footnotetext{
${ }^{27}$ Clearly, there exist substantial non-linearities in the elasticities of $D_{N}$ and $D_{Y}$ with respect to parameters. We compute the elasticities after a $1 \%$ change in the respective parameters.

${ }^{28}$ We re-calibrate and re-estimate the model, including the law of motion for $q$.
} 
the unemployment rate is smaller compared to the benchmark model, and the output loss due to the 'reallocation channel' shrinks.

\begin{tabular}{c|c|c|}
\hline \hline Model & $D_{N}$ & $D_{Y}$ \\
\hline Benchmark & $0.37 \%$ & $-1.61 \%$ \\
$\underline{\mathrm{h}}=0.975$ & $0.35 \%$ & $-1.19 \%$ \\
Prob. of STW $>0$ & $0.32 \%$ & $-1.92 \%$ \\
Hiring Credits & $0.20 \%$ & $0.17 \%$ \\
\hline
\end{tabular}

Table 5: Robustness

$D_{x}=\max \left|S-S^{\Xi}\right|$, where $x$ is respectively employment (N) and output (Y). $S$ and $S^{\Xi}$ denote the series of $N$ observations following a recession with (without) STW.

In the baseline model, the introduction of STW is always unexpected by firms. Row 3 of Table 5 shows results for the case when this assumption is removed. In this version of the model firms attach a positive probability to the introduction of the STW policy in a recession through an additional aggregate state. In a recession, the economy can transition into a new state $A^{\text {low, } \Xi}$, in which the STW policy is not active, but can be reached with positive probability 29 A transition from $A^{\text {low }}$ to $A^{\text {low, } \Xi}$ leads to a small increase in employment and total hours worked because the probability of being affected by the binding hours floor in the future is now smaller. The results in Table 5 compare the effects of a normal recession with those from a direct transition into STW. Compared to the benchmark case the positive employment effects are smaller and the negative output effects are larger.

Given that a downside of the STW policy is the adverse effect on hiring, a natural alternative to the STW policy could be hiring credits. Results are shown in the last row of Table5. Instead of preventing job destruction, this policy incentivizes job creation through a subsidy $\kappa$ for each new vacancy that is created, lowering hiring costs to $(1-\kappa) c_{v}{ }^{30}$ We solve the model for $\kappa=0.25$. Our results show that the hiring credits' potential to mitigate the increase in unemployment during a recession is limited. Because a large number of firms enter the labor adjustment region following the negative productivity shock, the unemployment rate spikes on impact. The hiring credits hardly affect this behavior because they have virtually no effect on shrinking firms. Firms that are hiring during the recession benefit from the hiring credits and increase their level of employment. This leads to a faster return to pre-recession levels of unemployment compared to a recession without the hiring credits policy, but no change in the initial increase. Hiring credits increase the correlation between firm-level employment and productivity. More labor is flowing to the firms with the highest productivity growth, generating positive output effects ${ }^{31}$ In 'sclerotic' labor markets, where hiring and firing is less prevalent than in more dynamic economies,

\footnotetext{
${ }^{29}$ In this scenario there are four possible aggregate states, $\left\{A^{\text {high }}, A^{\text {low }}, A^{\text {low }, \Xi}, A^{\Xi}\right\}$. The aggregate transition matrix takes the following form:

$$
\Pi=\underset{A^{\text {low }}, \Xi}{A^{\text {high }}}\left(\begin{array}{cccc}
A^{\text {high }} & A^{\text {low }} & A^{\text {low }, \Xi} & A^{\Xi} \\
\rho & 1-\rho & 0 & 0 \\
1-\rho & \rho-(1-\pi) & 1-\pi & 0 \\
1-\rho & 0 & \rho-(1-\pi) & 1-\pi \\
1-\rho & 0 & \rho-\pi & \pi
\end{array}\right)
$$

${ }^{30}$ The tax revenue needed to finance this policy are $c_{v} \cdot \kappa$ times the number of vacancies created.

${ }^{31}$ The effectiveness of hiring credits is limited, even when $\kappa$ is set to a higher level. The reason is that the increase in the vacancyfilling probability $q$ at the beginning of a recession is decreasing in $\kappa$. This has the effect of offsetting the reduction in hiring costs
} 
the effectiveness of incentivizing job creation is limited.

\subsection{Welfare Implications}

We use our model to assess the welfare implications of STW. While the STW policy increases employment relative to a recession without STW, it also lowers total output, making the overall welfare effects ambiguous ex-ante.

We distinguish between welfare effects for firms and workers. We subdivide firms into four groups according to their employment (high/low) and productivity levels (high/low), relative to the median. Employed workers are grouped in a similar fashion, depending on their employer, while unemployed workers are homogeneous.

In a recession with STW the value of currently unemployed workers is affected in two ways relative to a recession without STW. First, because an increase in unemployment is prevented, the job-finding probability $\phi=q \theta$ falls by less than during a recession without STW. However, the policy is financed through a lumpsum tax $\tau$ on all workers in the labor force, including the unemployed. In our calibrated model the costs of the policy (see Equation (16) ) amount to $1.4 \%$ of current output. For the unemployed, this negative effect on welfare outweighs the effect of the higher job-finding rate. However, the effects are small, welfare of the current unemployed changes by $-0.026 \%$ of its value during an expansion.

Workers benefit from the STW policy because it reduces the probability of being fired. Additionally, the disutility from working falls. However, as for the unemployed, the costs of the policy are shared equally while some workers do not work in firms that use STW. Table 6 shows the welfare effects for four different types of workers, grouped by the type of firm they are working for. Workers in firms with low productivity $\varepsilon$ are benefiting the most from the policy, because those firms are most likely to put workers on STW. For workers in high productivity firms the benefits of the policy are noticeably smaller. For workers in firms that have the most growth potential (low $n$, high $\varepsilon$ ), the costs outweigh the benefits.

\begin{tabular}{|c|c|c|}
\hline \hline & $\varepsilon_{\text {low }}$ & $\varepsilon_{\text {high }}$ \\
\hline$n_{\text {low }}$ & $0.1134 \%$ & $-0.0080 \%$ \\
& 0.47 & 0.13 \\
$n_{\text {high }}$ & $0.0768 \%$ & $0.0166 \%$ \\
& 0.03 & 0.37 \\
\hline
\end{tabular}

Table 6: Welfare of Employed Workers.

The cells show the difference in worker values during a recession with STW compared to without STW normalized by the value in expansions. The pre-recession share of firms in each bin is shown in parentheses below.

We also computed the relative worker welfare gains from STW by whether or not their matched firm used the STW policy. Workers in STW firms have an average welfare increase of $0.0631 \%$ of pre-recession welfare, while their counterparts see a decrease by $-0.0027 \%$.

A similar picture emerges for firm values, as we show in Table 7 . The firms benefiting the most from the policy are those that have high employment and low productivity. As shown above, those are precisely the firms that use the STW policy. Firms that do not use the policy still benefit, because of the additional flexibility. But their value increases by less because of the changes in the vacancy-filling probability $q$.

induced by higher $\kappa$. 
The average value of firms that actively use STW increases by $0.0068 \%$ of pre-recession value, while the average change in firm value for the remaining firms is $-0.0032 \%$.

\begin{tabular}{|c|c|c|}
\hline \hline & $\varepsilon_{\text {low }}$ & $\varepsilon_{\text {high }}$ \\
\hline$n_{\text {low }}$ & $0.0051 \%$ & $0.0013 \%$ \\
& 0.47 & 0.13 \\
$n_{\text {high }}$ & $0.0081 \%$ & $0.0033 \%$ \\
& 0.03 & 0.37 \\
\hline
\end{tabular}

Table 7: Changes in Firm Values

The cells show the difference in firm values during a recession with STW compared to without STW, normalized by the value in expansions. The pre-recession share of firms in each bin is shown in parentheses below.

\subsection{Implications of the Model}

This final section contains two exercises. The first one tests the model's prediction of lower aggregate job creation following the use of STW. The second one evaluates a counter-factual to study German output growth and unemployment in the absence of the STW policy.

\subsubsection{Job Creation in Germany}

The macro data on job creation and job destruction supports the model prediction of lower aggregate job creation following the use of STW. Because our micro data only contains firms in the manufacturing sector, generating a 'control group' of firms that did not use the STW policy is not possible. We can, however, compare the manufacturing sector, in which the uptake of the policy was primarily located, to other sectors, in particular the service sector, where the use of STW was much less prevalent. We use aggregated micro data of worker flows from the German Federal Employment Agency made available by the Institute for Employment Research (IAB) as reported in Ravenna and Schott (2016) ${ }^{32}$

We group firms into three sectors (manufacturing, services, and others) and obtain the stocks of total employment and the flows of newly created jobs by sector between 1976 and 2014. The data are seasonally adjusted, quarterly averages of monthly flows. Our empirical strategy consists of testing for a significant difference in job creation in manufacturing compared to other sectors during the 'STW policy' period.

We estimate the following model:

$$
J C_{j t}=\beta_{0}+\beta_{1} \cdot \mathrm{STW}_{t}+\beta_{2} \cdot \mathrm{Manu}_{j}+\beta_{3} \cdot \mathrm{Manu}_{j} \cdot \mathrm{STW}_{t}+\gamma X+\varepsilon_{j t} .
$$

Job creation in sector $j$ at time $t$ depends on a vector of controls $X$, the STW policy, which is a dummy variable that takes the value of one between the second quarter of 2009 and the last quarter of 2010, a dummy for the manufacturing sector, and an interaction term between the policy dummy and the manufacturing dummy. The coefficient of interest is $\beta_{3}$, which estimates the difference in job creation in manufacturing and other sectors

\footnotetext{
${ }^{32}$ Publicly available aggregate data on job creation, job destruction, and total employment by sector is available from the German Employment Agency. Our empirical results are robust to using this alternative data source (results are available upon request) but because that data is annual and only available starting in 2004 we gave priority to the IAB data.
} 


\begin{tabular}{|c|c|c|c|c|c|c|c|}
\hline & $\begin{array}{c}(1) \\
\log \mathrm{JC}\end{array}$ & $\begin{array}{c}(2) \\
\log \mathrm{JC}\end{array}$ & $\begin{array}{c}(3) \\
\log \mathrm{JC}\end{array}$ & $\begin{array}{c}(4) \\
\log \mathrm{JC}\end{array}$ & $\begin{array}{c}(5) \\
\text { JC rate }\end{array}$ & $\begin{array}{c}(6) \\
\text { JC rate }\end{array}$ & $\begin{array}{c}(7) \\
\text { JC rate }\end{array}$ \\
\hline STW & $\begin{array}{c}-0.0479 \\
(-0.22)\end{array}$ & $\begin{array}{c}0.0328 \\
(0.22)\end{array}$ & $\begin{array}{c}-0.0400 \\
(-0.30)\end{array}$ & $\begin{array}{l}-0.108 \\
(-0.50)\end{array}$ & $\begin{array}{c}-0.00925 \\
(-1.18)\end{array}$ & $\begin{array}{c}-0.00766 \\
(-1.88)\end{array}$ & $\begin{array}{c}-0.00512 \\
(-0.90)\end{array}$ \\
\hline Manu & $\begin{array}{c}-0.420^{* *} \\
(-3.22)\end{array}$ & $\begin{array}{c}-0.420^{* *} \\
(-3.22)\end{array}$ & $\begin{array}{c}-0.417^{* *} \\
(-3.14)\end{array}$ & $\begin{array}{c}-0.417^{* * *} \\
(-4.97)\end{array}$ & $\begin{array}{c}-0.0442^{* * *} \\
(-10.35)\end{array}$ & $\begin{array}{c}-0.0442^{* * *} \\
(-10.46)\end{array}$ & $\begin{array}{c}-0.0442^{* * *} \\
(-118.80)\end{array}$ \\
\hline Manu*STW & $\begin{array}{c}-0.498^{*} \\
(-2.31)\end{array}$ & $\begin{array}{c}-0.498^{*} \\
(-2.31)\end{array}$ & $\begin{array}{c}-0.500^{*} \\
(-2.30)\end{array}$ & $\begin{array}{c}-0.500^{*} \\
(-2.09)\end{array}$ & $\begin{array}{c}-0.0245^{* *} \\
(-3.14)\end{array}$ & $\begin{array}{c}-0.0246^{* *} \\
(-3.11)\end{array}$ & $\begin{array}{c}-0.0246^{* * *} \\
(-4.23)\end{array}$ \\
\hline GDP Growth & & & $\begin{array}{c}0.0175 \\
(1.82)\end{array}$ & $\begin{array}{c}0.0238 \\
(1.19)\end{array}$ & & $\begin{array}{c}0.00165^{*} \\
(2.20)\end{array}$ & $\begin{array}{c}0.00142 \\
(1.42)\end{array}$ \\
\hline Unemployment Rate & & & $\begin{array}{c}-0.0327^{* * *} \\
(-4.17)\end{array}$ & $\begin{array}{c}-0.0439 \\
(-1.59)\end{array}$ & & $\begin{array}{c}-0.00334^{* * *} \\
(-9.15)\end{array}$ & $\begin{array}{c}-0.00292^{* * *} \\
(-4.26)\end{array}$ \\
\hline Constant & $\begin{array}{c}8.102^{* * *} \\
(62.17)\end{array}$ & $\begin{array}{c}8.282^{* * *} \\
(16.31)\end{array}$ & $\begin{array}{c}8.385^{* * *} \\
(16.38)\end{array}$ & $\begin{array}{c}8.326^{* * *} \\
(22.56)\end{array}$ & $\begin{array}{l}0.707^{* * *} \\
(165.28)\end{array}$ & $\begin{array}{c}0.738^{* * *} \\
(84.94)\end{array}$ & $\begin{array}{l}0.740^{* * *} \\
(120.08)\end{array}$ \\
\hline Time Trend & & Yes & Yes & & & Yes & \\
\hline Sector-Time Trend & & & & Yes & & & Yes \\
\hline Observations & 465 & 465 & 462 & 462 & 465 & 462 & 462 \\
\hline
\end{tabular}

Table 8: Job Creation and STW

during the time of the policy. The vector of control variables $X$ can contain GDP, the unemployment rate, or a (sector-specific) time trend. Results are shown in Table 8.

The dependent variable is either the logarithm of job creation or the job creation rate. The coefficient of interest, $\beta_{3}$, is negative and significant in all specifications. The results suggest that job creation (rates) in manufacturing were significantly negatively affected by the STW policy ${ }^{33}$

While these results do not in themselves provide conclusive evidence of our theoretical channel, they are in line with our predictions and with findings by related studies (e.g. Balleer et al. (2016)).

\subsubsection{GDP growth and unemployment}

Recall that Figure 9 shows the model's predictions of a recession with and without the STW policy. It is informative to relate these predictions of the model to the actual experience in Germany and other OECD countries. Based upon model calculations, in the absence of the policy, the decline in GDP would have been $5.3 \%$ and the unemployment rate would have been about four percentage points higher. These predictions are much closer to the OECD average.

\footnotetext{
${ }^{33}$ We found our results to be qualitatively robust to various alternative specifications. These include adding 2011 to the 'STW policy' years, removing the residual sector category, estimating the effect in a panel starting in 1995 (after much of the transition dynamics associated with the reunification had played out), and including previous incidences of widely-used STW programs (19911993) in the STW dummy. Results are available upon request.
} 


\section{Conclusion}

This paper studies the employment and productivity effects of short-time work in Germany between 2009 and 2010. The policy facilitates reductions in hours worked per employee with the goal of preventing layoffs. Using confidential German micro-level data we estimate a search model with heterogeneous multi-worker firms. Our findings suggest that STW was successful in preventing an increase in unemployment. However, the policy leads to a decrease in the allocative efficiency of the German labor market resulting in significant output losses. This

reflects a reduction in the equilibrium value of the vacancy filling rate induced by the policy intervention. The aggregate data on job creation confirms the importance of this channel. 


\section{References}

Bachmann, R. And C. Bayer (2014): "Investment Dispersion and the Business Cycle," American Economic Review, 104, 1392-1416.

Balleer, A., B. Gehrke, W. Lechthaler, And C. Merkl (2016): "Does short-time work save jobs? A business cycle analysis," European Economic Review, 84, 99-122.

Bartelsman, E., J. Haltiwanger, And S. Scarpetta (2013): "Cross-Country Differences in Productivity: The Role of Allocation and Selection," American Economic Review, 103, 305-334.

Boeri, T. And H. Bruecker (2011): "Short-time work benefits revisited: some lessons from the Great Recession," Economic Policy, 26, 697-765.

Braun, H. And B. Brügemann (2014): "Welfare Effects of Short-Time Compensation," CESifo Working Paper Series 5063, CESifo Group Munich.

Brügemann, B., P. Gautier, And G. Menzio (2015): "Intra Firm Bargaining and Shapley Values," Working Paper 21508, National Bureau of Economic Research, dOI: 10.3386/w21508.

Burda, M. C. And J. Hunt (2011): "What Explains the German Labor Market Miracle in the Great Recession," Brookings Papers on Economic Activity, 42, 273-335.

Burdett, K. And R. Wright (1989): "Unemployment Insurance and Short-Time Compensation: The Effects on Layoffs, Hours per Worker, and Wages," Journal of Political Economy, 97, 1479-1496.

Cahuc, P. And S. Carcillo (2011): "Is short-time work a good method to keep unemployment down?" Nordic Economic Policy Review, 133-164.

Cooper, R., J. Haltiwanger, And J. L. Willis (2007): "Search frictions: Matching aggregate and establishment observations," Journal of Monetary Economics, 54, 56-78.

Cooper, R. W. And I. Schotт (2016): "Capital Reallocation and Aggregate Productivity," Working Paper 19715, National Bureau of Economic Research.

Dustmann, C., B. Fitzenberger, U. Schönberg, And A. Spitz-Oener (2014): "From Sick Man of Europe to Economic Superstar: Germany's Resurgent Economy," Journal of Economic Perspectives, 28, 167-188.

Elsby, M. W. L. And R. Michaels (2013): "Marginal Jobs, Heterogeneous Firms, and Unemployment Flows," American Economic Journal: Macroeconomics, 5, 1-48.

Engbom, N., E. Detragiache, And F. Raei (2015): "The German Labor Market Reforms and PostUnemployment Earnings," IMF Working Paper 15/162, International Monetary Fund.

Heathcote, J., K. Storesletten, And G. L. Violante (2009): "Quantitative Macroeconomics with Heterogeneous Households," Annual Review of Economics, 1, 319-354. 
Hoffmann, F. And T. Lemieux (2016): "Unemployment in the Great Recession: A Comparison of Germany, Canada, and the United States," Journal of Labor Economics, 34.

Hsieh, C.-T. And P. J. Klenow (2009): "Misallocation and Manufacturing TFP in China and India," The Quarterly Journal of Economics, 124, 1403-1448.

Hunt, J. (1998): "Hours Reductions as Work-Sharing," Brookings Papers on Economic Activity, 29, 339-381.

_ (1999): "Has Work-Sharing Worked in Germany?" The Quarterly Journal of Economics, 114, 117-148.

Kohlbrecher, B., C. Merkl, And D. Nordmeier (2016): "Revisiting the matching function," Journal of Economic Dynamics and Control, 69, 350-374.

Krause, M. U. And H. Uhlig (2012): "Transitions in the German labor market: Structure and crisis," Journal of Monetary Economics, 59, 64-79.

Kruppe, T. And T. Scholz (2014): "Labour hoarding in Germany : employment effects of short-time work during the crises," IAB Discussion Paper 201417, Institute for Employment Research, Nuremberg, Germany.

Krusell, P. And A. A. Smith (1998): "Income and Wealth Heterogeneity in the Macroeconomy," Journal of Political Economy, 106, 867-896.

Kudoh, N. And M. SASAKI (2011): "Employment and hours of work," European Economic Review, 55, $176-192$.

Marimon, R. And F. Zilibotti (2000): "Employment and distributional effects of restricting working time," European Economic Review, 44, 1291-1326.

Niedermayer, K. And J. Tilly (2016): "Employment and Welfare Effects of Short-Time Work in Germany," Annual Conference 2016 (Augsburg): Demographic Change 145842, Verein für Socialpolitik / German Economic Association.

Ravenna, F. And I. Schott (2016): "Time-varying Worker Heterogeneity and the Incentives to Hire: Evidence from the German Labor," .

Silva, J. I. ANd M. Toledo (2009): "Labor Turnover Costs and the Behavior of Vacancies and Unemployment," Macroeconomic Dynamics, 13, 76-96.

Stole, L. A. And J. Zwiebel (1996): "Intra-Firm Bargaining under Non-Binding Contracts," The Review of Economic Studies, 63, 375-410.

Tijdens, K., M. van Klaveren, R. Bispinck, H. Dribbusch, And F. Öz (2014): "Wage and workforce adjustments in the economic crisis in Germany and the Netherlands," European Journal of Industrial Relations, 20, 165-183. 


\section{A Data}

Micro Data A detailed description the micro data we are using can be found (only in German) at http://www . forschungsdatenzentren.de/bestand/afid-panel_industriebetriebe/fdz_afid-panel_industriebetriebe_ metadaten.pdf. The panel includes all plants which belong to up to 68'000 firms whose main activity or a significant share of activity lies in manufacturing or mining. Only plants within Germany are registered. The underlying data is collected on a monthly basis and then aggregated by year. The employment change distribution is shown in Figure 13

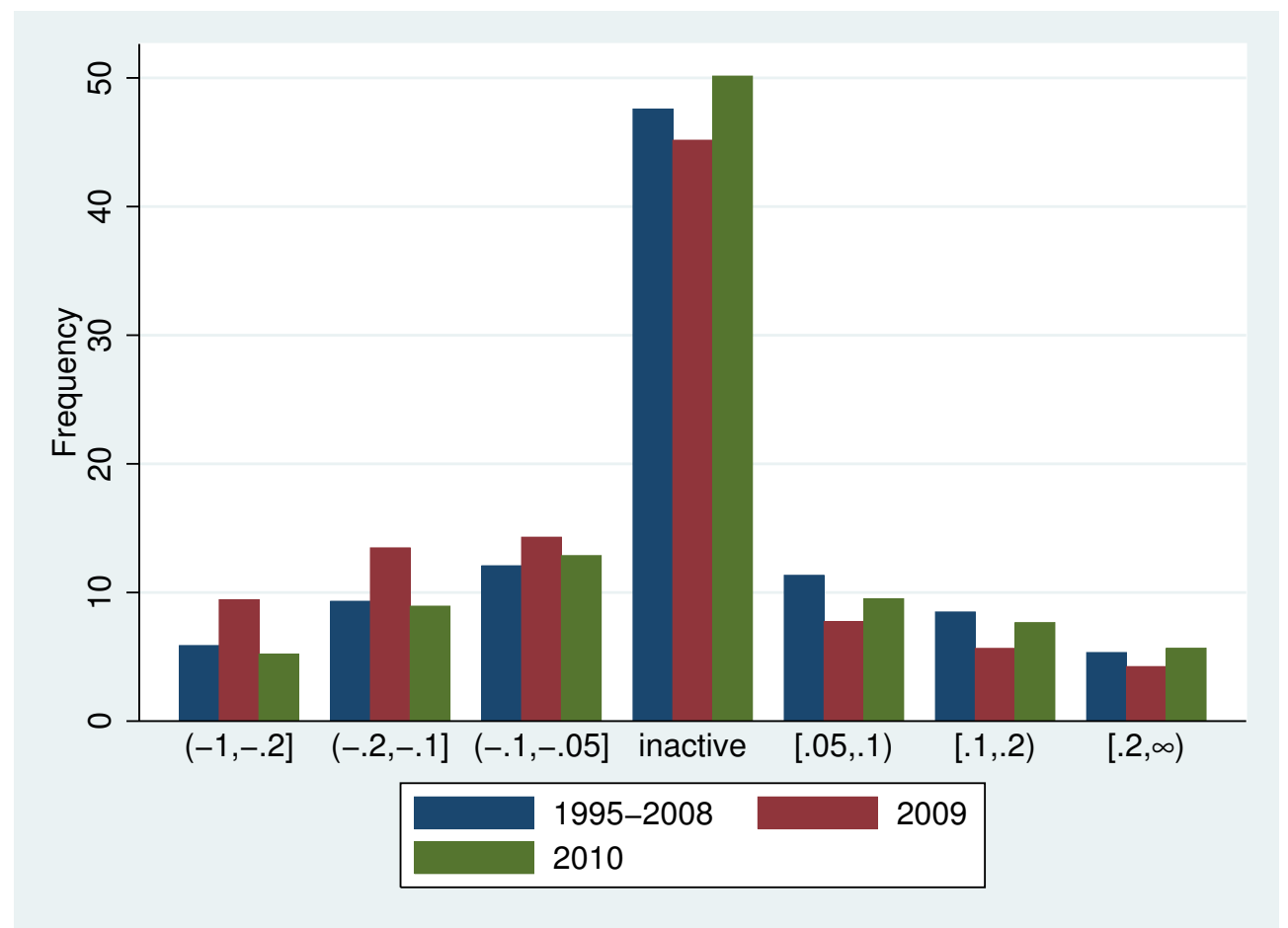

Figure 13: Changes in Average Employment

Distribution of annual average employment changes. Source: Authors' calculations from the micro data from the AFiD-Panel Industriebetriebe, Germany.

Macro Data The remaining graphs show aggregate data on the use of STW in Germany during the period under consideration in this study. The data comes from the German Federal Employment Agency 34 Figure 14 shows the number of workers and firms using STW for economic reasons ${ }^{35}$

Figure 15 shows the distribution of hours reductions for workers using all types of STW. The vast majority of working time reductions during the 2009 recession were between $0 \%$ and 50\%. Figure 16 shows the distribution of firm sizes for workers using all types of STW. It shows that most workers who were put on STW were working

\footnotetext{
${ }^{34}$ It should be noted that the statistics regarding the use of short-time work come from a more comprehensive data source starting in January 2009. We refer to the Federal Employment Agency's website for details.

${ }^{35}$ As was pointed out in the main text, we concentrate on the use of STW due to economic distress ( $\left.§ 170\right)$. This decomposition in the aggregate numbers is available since 2008. The overwhelming majority of STW use is due to economic distress. Data for other uses of STW is available upon request.
} 


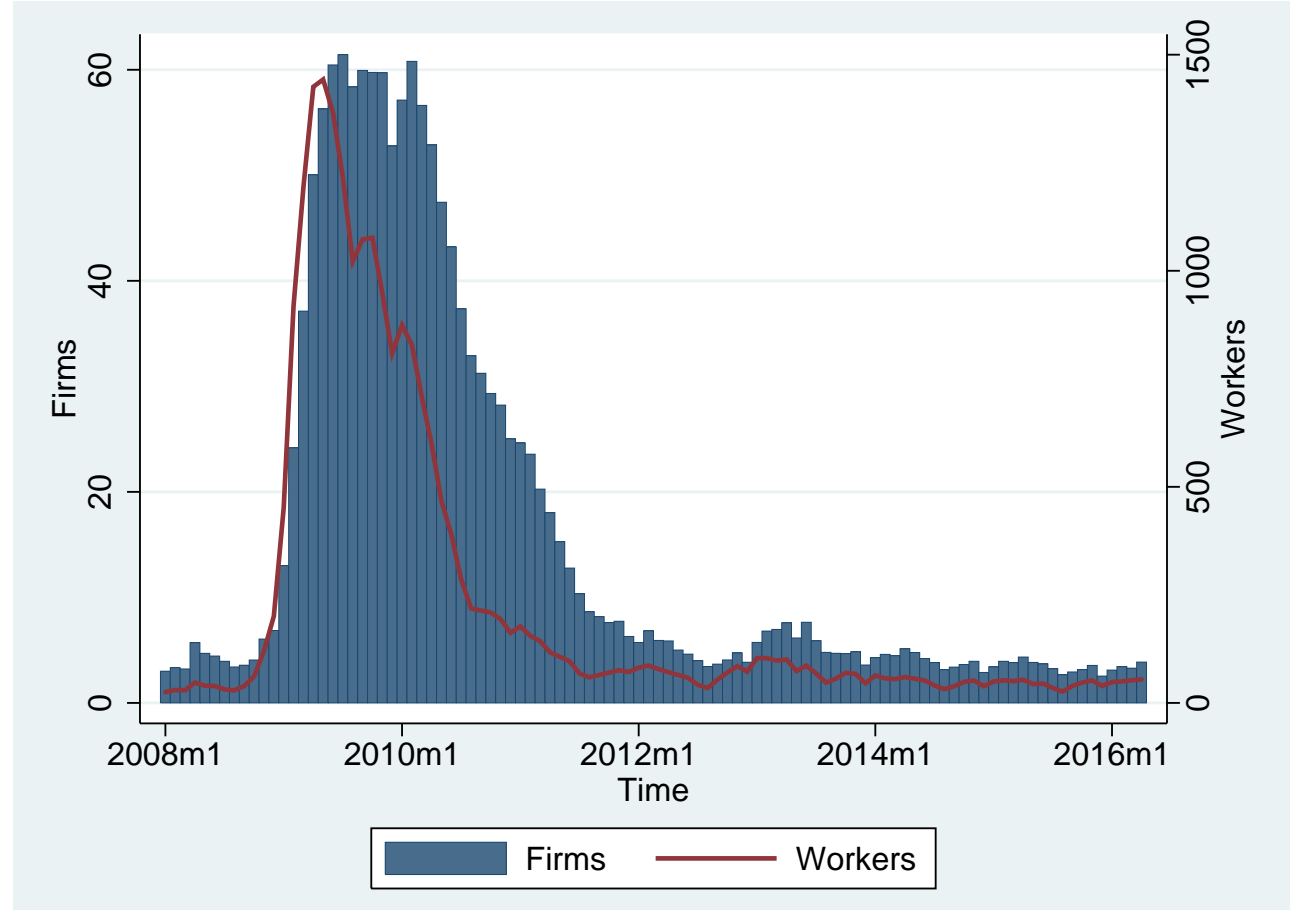

Figure 14: Workers and Firms using STW

STW use of workers and firms between 2008 and 2010 in 1,000. Source: German Employment Agency 


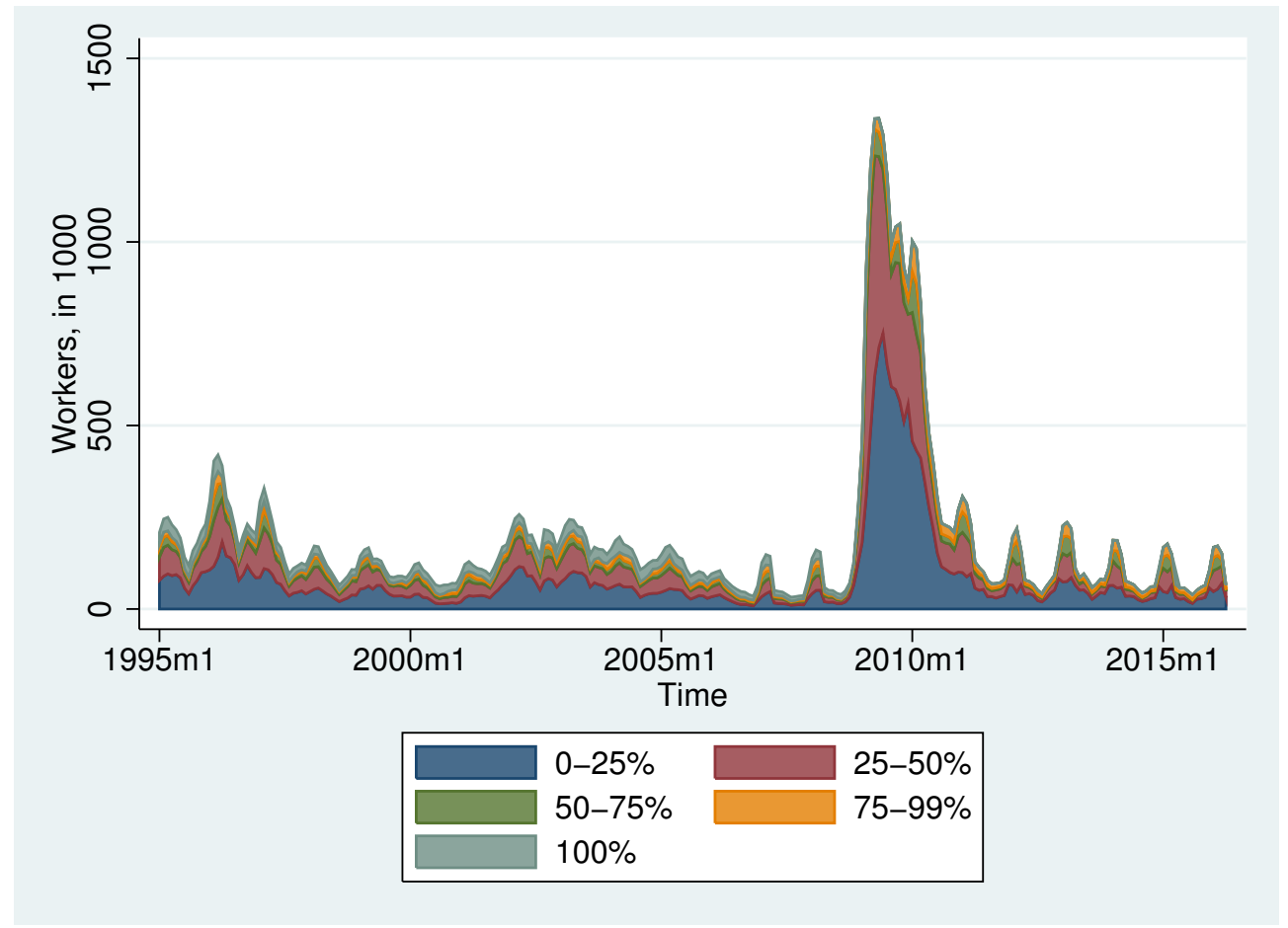

Figure 15: Hours Reductions and STW

STW use between 1995 and 2010 by amount of hours reductions. Source: German Employment Agency

in medium and large firms.

Figure 17 shows the importance of manufacturing for the uptake of the STW policy. The graph is drawn by averaging over all observations from 2009. More than $80 \%$ of workers (or $78 \%$ of full-time equivalents) who were on STW during 2009 worked in manufacturing. Manufacturing firms represented around $45 \%$ of all firms who used STW in 2009. The numbers refer to STW for economic reasons. 


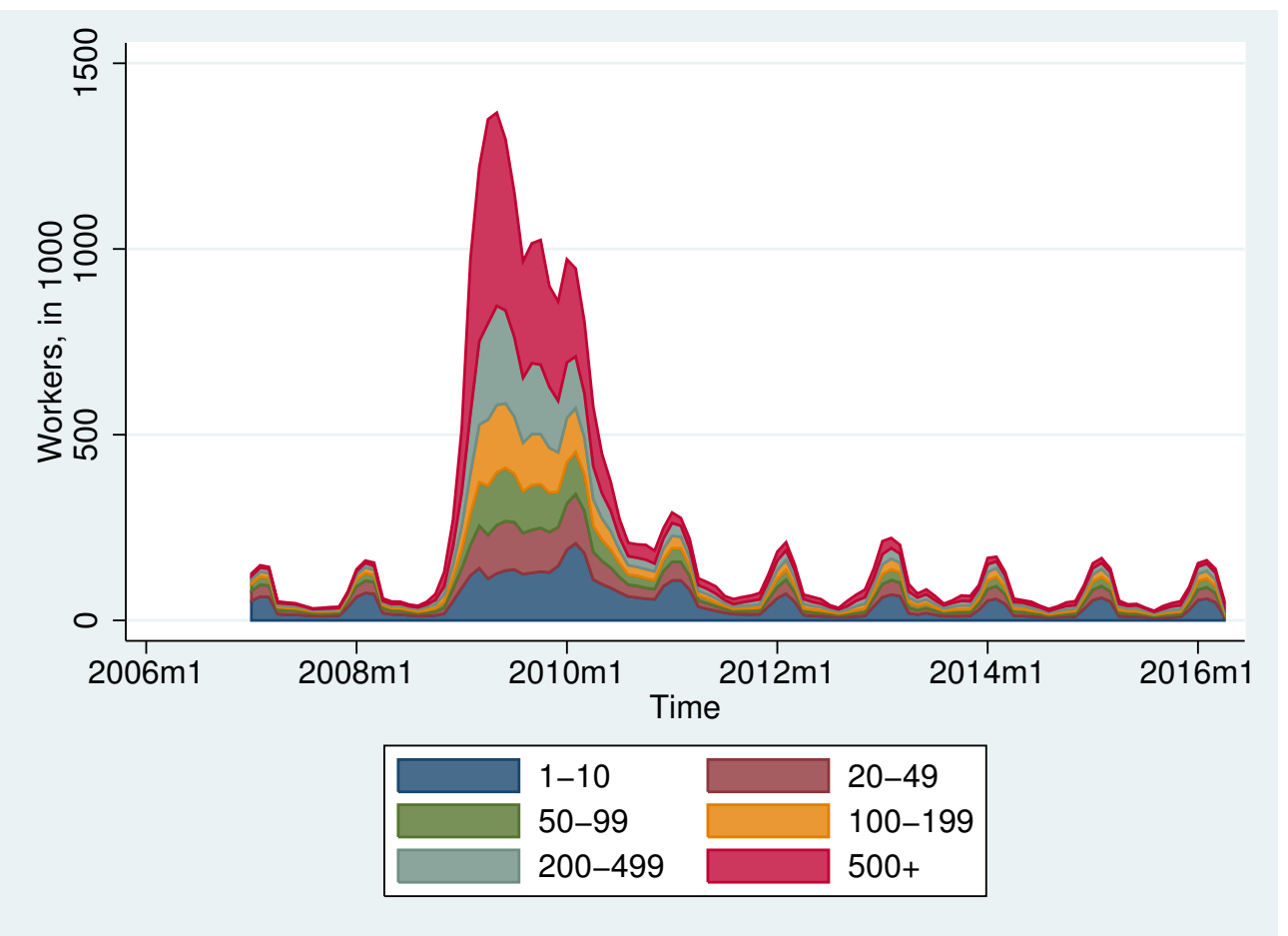

Figure 16: Firm Size and STW

STW use between 1995 and 2010 by Firm Size. Source: German Employment Agency

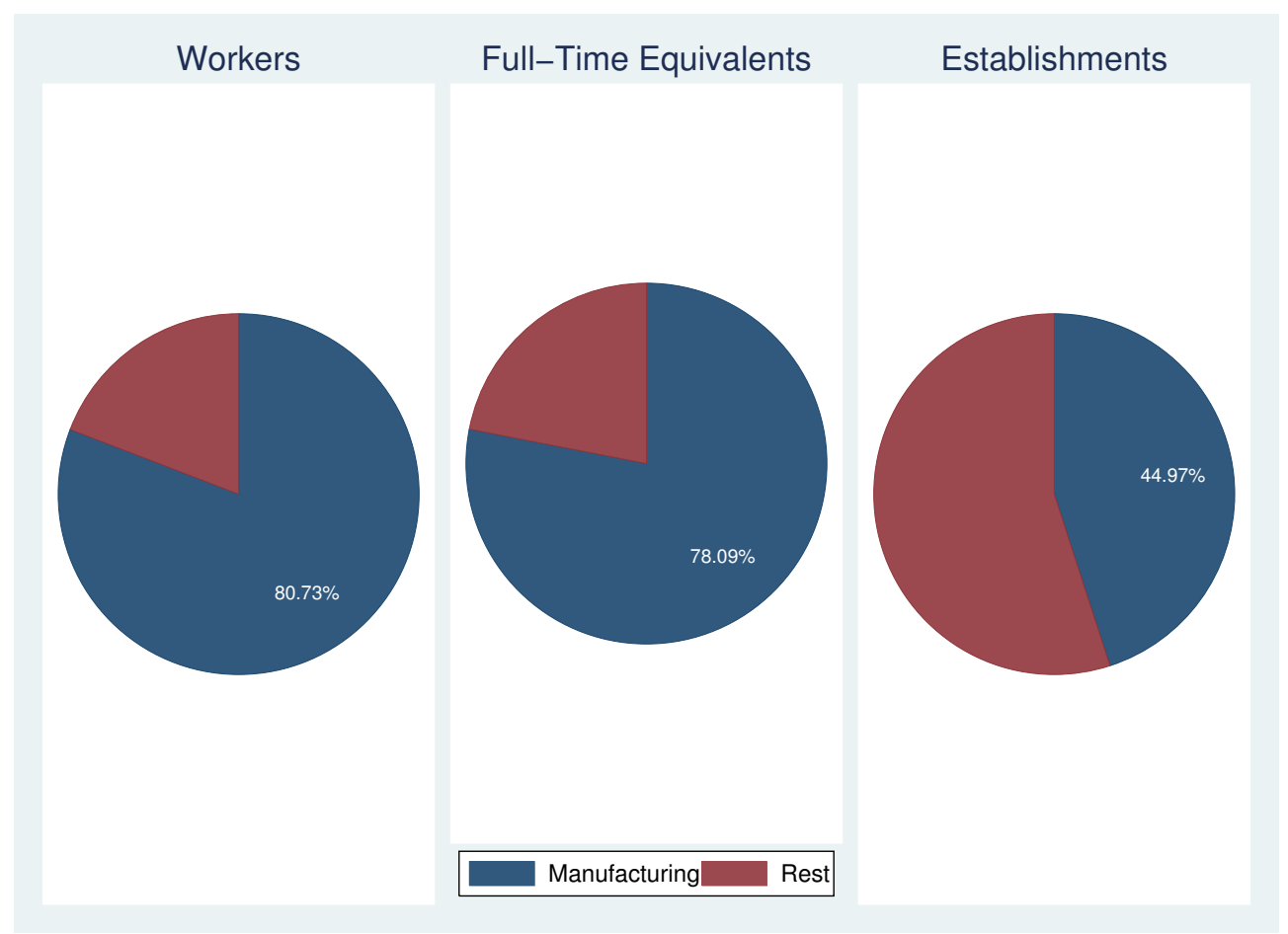

Figure 17: STW by Sector. Source: German Employment Agency STW use in 2009 by Sector. Source: German Employment Agency 


\section{B The Wage}

Note from the firm's envelope condition that the firm's marginal surplus has a recursive structure. It can be written as

$$
S(\varepsilon, n)=\varepsilon h F_{L}(h \cdot n)-\omega(h, n, \varepsilon) h-\omega_{n}(h, n, \varepsilon) h n+\quad+\beta \int_{\psi_{v}(n)}^{\infty} \frac{c_{v}}{q} d G\left(\varepsilon^{\prime} \mid \varepsilon\right)+\beta \int_{\psi(n)}^{\psi_{v}(n)} S\left(\varepsilon^{\prime}, n\right) d G\left(\varepsilon^{\prime} \mid \varepsilon\right)
$$

Next, we find an expression for the left-hand side of equation (7). The value of a worker who is unemployed at the beginning of the period is given by

$$
W^{u}=b+\beta\left[(1-\phi) W^{u \prime}+\phi \int_{0}^{\infty} \int_{\psi(n)}^{\infty} \frac{W^{e}\left(\varepsilon^{\prime}, \psi_{v}^{-1}(\varepsilon)\right)}{1-G\left(\psi_{v}(n)\right)} d G\left(\varepsilon^{\prime} \mid \varepsilon\right) d H(n)\right]
$$

Upon finding a job today, which occurs with probability $\phi$, the new job must be in a firm that is posting vacancies. This implies that $\varepsilon>\psi_{v}\left(n_{-1}\right)$ today, and that $n=\psi_{v}^{-1}(\varepsilon)$. The value of $\varepsilon^{\prime}$ is unknown, the worker is taking the expectation over it ${ }^{36}$ Under Nash sharing(7) the worker's expected surplus in an expanding firm is $W^{e}\left(\varepsilon^{\prime}, \psi_{v}^{-1}\left(\varepsilon^{\prime}\right)\right) d G\left(\varepsilon^{\prime} \mid \varepsilon\right)-W^{u^{\prime}}=\frac{\eta}{1-\eta} V_{n}\left(\varepsilon^{\prime}, \psi_{v}^{-1}(\varepsilon)\right)$. From the first order condition of a hiring firm (3) we know that $S\left(\varepsilon^{\prime}, \psi_{v}^{-1}\left(\varepsilon^{\prime}\right)\right)=\frac{c_{v}}{q}$. Therefore

$$
\begin{gathered}
W^{u}=b+\beta\left[(1-\phi) W^{u \prime}+\phi\left(\frac{\eta}{1-\eta} \frac{c_{v}}{q}+W^{u \prime}\right)\right] \\
W^{u}=b+\beta W^{u \prime}+\beta \phi \frac{\eta}{1-\eta} \frac{c_{v}}{q} .
\end{gathered}
$$

The value of an employed worker can be written as

$$
\begin{aligned}
& W^{e}(\varepsilon, n)=\omega(h, \varepsilon, n) \cdot h-\xi(h) \quad+ \\
& \begin{aligned}
\beta\left\{\int_{0}^{\psi(n)}\left[\tilde{s} W^{u \prime}+(1-\tilde{s}) W^{e}\left(\varepsilon^{\prime}, \psi^{-1}\left(\varepsilon^{\prime}\right)\right)\right] d G\left(\varepsilon^{\prime} \mid \varepsilon\right)\right. \\
\left.\quad+\int_{\psi(n)}^{\psi_{v}(n)} W^{e}\left(\varepsilon^{\prime}, n\right) d G\left(\varepsilon^{\prime} \mid \varepsilon\right)+\int_{\psi_{v}(n)}^{\infty} W^{e}\left(\varepsilon^{\prime}, \psi_{v}^{-1}\left(\varepsilon^{\prime}\right)\right) d G\left(\varepsilon^{\prime} \mid \varepsilon\right)\right\} .
\end{aligned}
\end{aligned}
$$

A worker in a firm in state $(\varepsilon, n)$ receives an instantaneous compensation $\omega(h, \varepsilon, n)$ per hour worked and suffers the utility cost. If the firm receives $\varepsilon^{\prime}<\psi(n)$ next period, it will fire workers. In that case workers are selected to be fired at random, so with endogenous probability $\tilde{s}$ the worker will be unemployed, receiving $W^{u \prime}$. With the counter-probability $(1-\tilde{s})$ he remains employed in a firm that will be in state $\left(\varepsilon^{\prime}, \psi^{-1}\left(\varepsilon^{\prime}\right)\right)$. Nash-sharing implies that $W^{e}\left(\varepsilon^{\prime}, \psi^{-1}\left(\varepsilon^{\prime}\right)\right)-W^{u \prime}=\frac{\eta}{1-\eta} S\left(\varepsilon^{\prime}, \psi^{-1}\left(\varepsilon^{\prime}\right)\right)$. From the first order condition we know that $S\left(\varepsilon^{\prime}, \psi^{-1}\left(\varepsilon^{\prime}\right)\right)=0$, implying $W^{u \prime}=W^{e}\left(\varepsilon^{\prime}, \psi^{-1}\left(\varepsilon^{\prime}\right)\right)$. If the firm hires workers next period, employment

\footnotetext{
${ }^{36}$ Moreover, there is a distribution of employment levels, $H(n)$, over which an unemployed worker will take expectations when evaluating the expected future benefits of being hired (over the employment levels of all hiring firms today).
} 
will be $\psi_{v}^{-1}\left(\varepsilon^{\prime}\right)$. We saw above that Nash sharing then implies that $W^{e}\left(\varepsilon^{\prime}, \psi_{v}^{-1}\left(\varepsilon^{\prime}\right)\right)-W^{u^{\prime}}=\frac{\eta}{1-\eta} \frac{c_{v}}{q}$. Finally, if the firm remains inactive, the expected value of an employed worker in the following period will be given by $W^{e}\left(\varepsilon^{\prime}, n\right)$. Nash sharing implies that $W^{e}\left(\varepsilon^{\prime}, n\right)-W^{u \prime}=\frac{\eta}{1-\eta} S\left(\varepsilon^{\prime}, n\right)$. Equation 24 can then be written as

$$
\begin{aligned}
& W^{e}(\varepsilon, n)=\omega(h, \varepsilon, n) \cdot h-\xi(h)+\beta\left\{\int_{0}^{\psi(n)} W^{u \prime} d G\left(\varepsilon^{\prime} \mid \varepsilon\right)+\right. \\
&\left.\int_{\psi(n)}^{\psi_{v}(n)}\left[W^{u \prime}+\frac{\eta}{1-\eta} S\left(\varepsilon^{\prime}, n\right)\right] d G\left(\varepsilon^{\prime} \mid \varepsilon\right)+\int_{\psi_{v}(n)}^{\infty}\left[W^{u \prime}+\frac{\eta}{1-\eta} \frac{c_{v}}{q}\right] d G\left(\varepsilon^{\prime} \mid \varepsilon\right)\right\} .
\end{aligned}
$$

After collecting the $W^{u \prime}$ terms we get

$$
\begin{aligned}
& W^{e}(\varepsilon, n)=\omega(h, \varepsilon, n) \cdot h-\xi(h)+\beta W^{u \prime}+ \\
& \beta \frac{\eta}{1-\eta} \int_{\psi(n)}^{\psi_{v}(n)} S\left(\varepsilon^{\prime}, n\right) d G\left(\varepsilon^{\prime} \mid \varepsilon\right)+\beta \frac{\eta}{1-\eta} \int_{\psi_{v}(n)}^{\infty} \frac{c_{v}}{q} d G\left(\varepsilon^{\prime} \mid \varepsilon\right) .
\end{aligned}
$$

Now we subtract $W^{u}$ from both sides in (26). On the right-hand side we use the expression for $W^{u}$ that was derived in 23 .

$$
\begin{aligned}
W^{e}(\varepsilon, n)-W^{u}=\omega(h, \varepsilon, n) \cdot h-\xi(h)-b-\beta \phi \frac{\eta}{1-\eta} \frac{c_{v}}{q}+ & \\
& \beta \frac{\eta}{1-\eta} \int_{\psi(n)}^{\psi_{v}(n)} S\left(\varepsilon^{\prime}, n\right) d G\left(\varepsilon^{\prime} \mid \varepsilon\right)+\beta \frac{\eta}{1-\eta} \int_{\psi_{v}(n)}^{\infty} \frac{c_{v}}{q} d G\left(\varepsilon^{\prime} \mid \varepsilon\right) .
\end{aligned}
$$

Using the Nash sharing rule in (7) this expression must be equal to $\frac{\eta}{1-\eta} S(\varepsilon, n)$, which comes from 20 .

$$
\begin{gathered}
\omega(h, \varepsilon, n) \cdot h-\xi(h)-b-\beta \phi \frac{\eta}{1-\eta} \frac{c_{v}}{q}+ \\
\beta \frac{\eta}{1-\eta} \int_{\psi(n)}^{\psi_{v}(n)} S\left(\varepsilon^{\prime}, n\right) d G\left(\varepsilon^{\prime} \mid \varepsilon\right)+\beta \frac{\eta}{1-\eta} \int_{\psi_{v}(n)}^{\infty} \frac{c_{v}}{q} d G\left(\varepsilon^{\prime} \mid \varepsilon\right)= \\
\frac{\eta}{1-\eta}\left\{h \cdot\left[\varepsilon F_{L}(h \cdot n)-\omega(h, n, \varepsilon)-\omega_{n}(h, n, \varepsilon) n\right]+\right. \\
\left.\beta \int_{\psi_{v}(n)}^{\infty} \frac{c_{v}}{q} d G\left(\varepsilon^{\prime} \mid \varepsilon\right)+\beta \int_{\psi(n)}^{\psi_{v}(n)} S\left(\varepsilon^{\prime}, n\right) d G\left(\varepsilon^{\prime} \mid \varepsilon\right)\right\}
\end{gathered}
$$

After canceling out the terms with the integrals, we obtain

$$
\omega(h, \varepsilon, n) \cdot h-\xi(h)-b-\beta \phi \frac{\eta}{1-\eta} \frac{c_{v}}{q}=\frac{\eta}{1-\eta}\left\{h \cdot\left[\varepsilon F_{L}(h \cdot n)-\omega(h, n, \varepsilon)-\omega_{n}(h, n, \varepsilon) n\right]\right\}
$$


The bargained wage thus solves the differential equation

$$
\omega(h, \varepsilon, n) \cdot h=(1-\eta)[b+\xi(h)]+\eta\left[\varepsilon h F_{L}(h \cdot n)+\beta \phi \frac{c_{v}}{q}-\omega_{n}(h, n, \varepsilon) \cdot h \cdot n\right] .
$$

\section{Additional Quantitative Results}

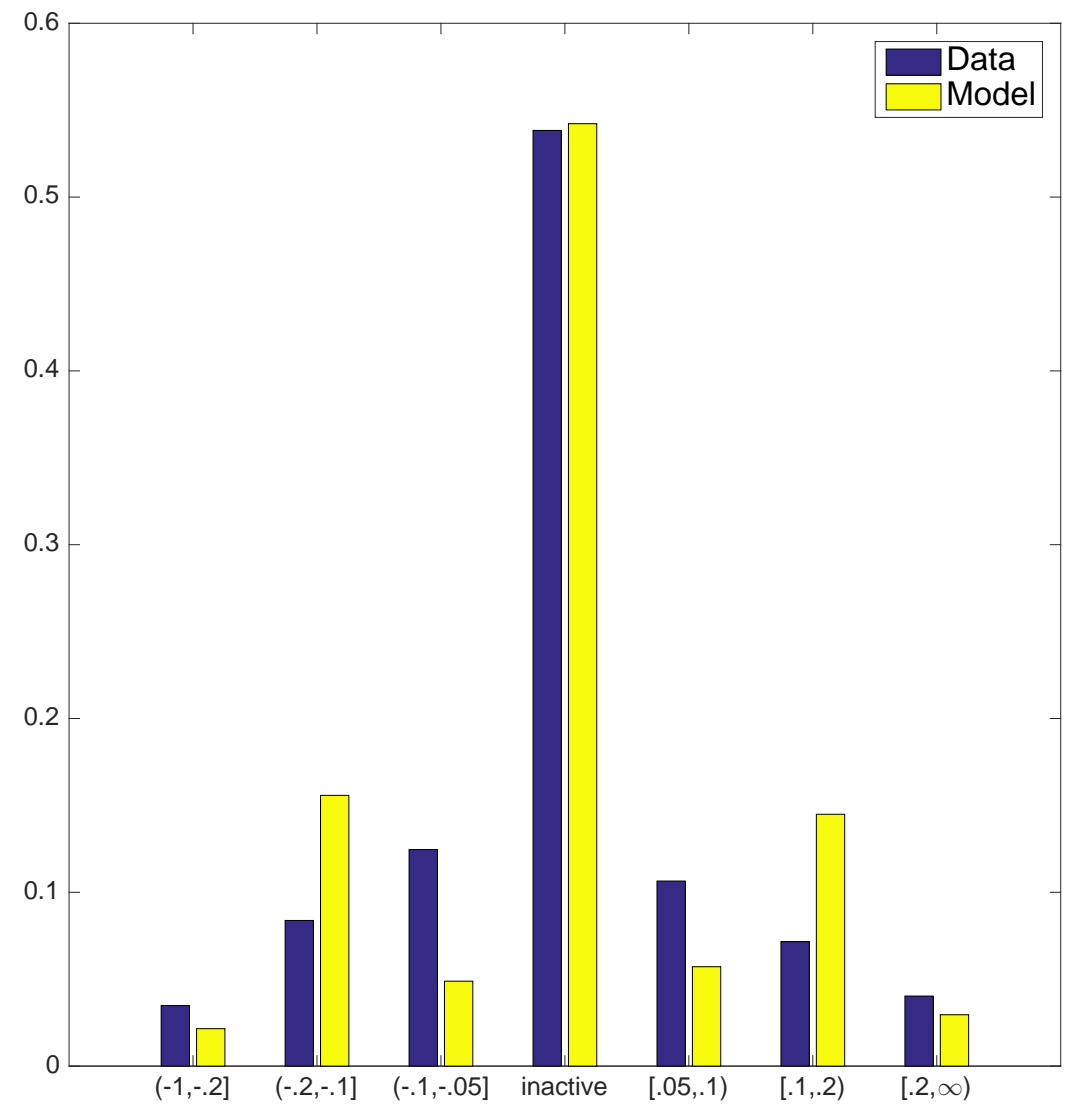

Figure 18: Changes in Hours per Worker

Hours Change Distribution. The data (model) is shown in blue (yellow). 


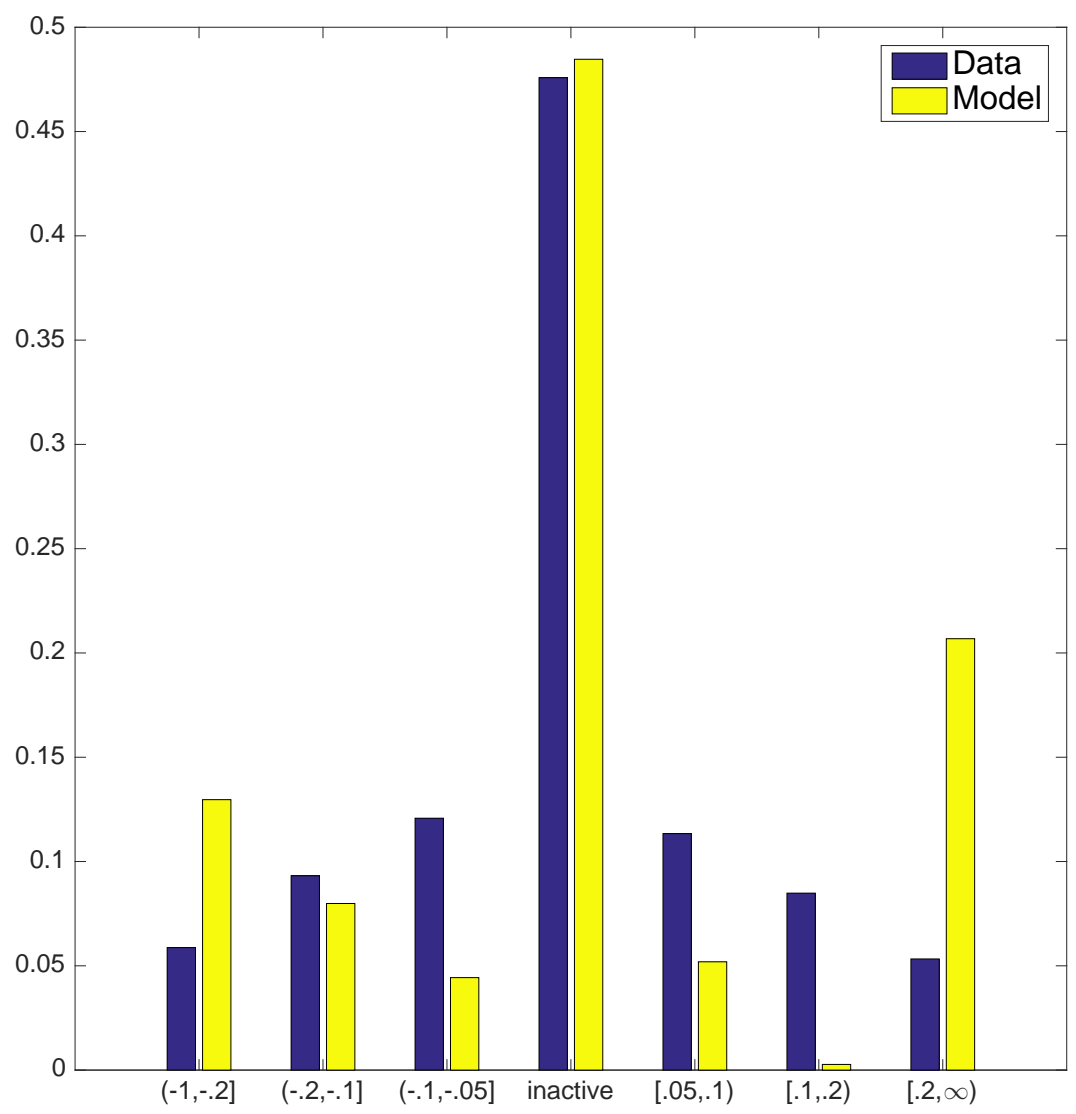

Figure 19: Changes in Employment

Employment Change Distribution. The data (model) is shown in blue (yellow). 